\title{
1 Predicting the conservation status of Europe's Data Deficient sharks and rays
}

2

3 Predicting status of Data Deficient sharks

4

5

6 Rachel H.L. Walls ${ }^{1 *}$, Nicholas K. Dulvy ${ }^{1}$

7

$8 \quad{ }^{1}$ Earth to Ocean Research Group, Department of Biological Sciences, Simon Fraser University,

9 Burnaby, BC, Canada

10

$11 *$ Corresponding author.

12 Contact: +1(778)251-8227, rwalls@sfu.ca (Rachel HL Walls)

13

14

15 Keywords: Aichi target, Chondrichthyes, Elasmobranchii, depth refuge, General Fisheries

16 Commission for the Mediterranean, Red List Index 


\section{ABSTRACT}

18 Shark and ray biodiversity is threatened primarily by overfishing and the globalisation of trade,

19 and Europe has been one of the most documented heavily fished regions for a relatively long

20 time. Yet, we have little idea of the conservation status of the hundreds of Data Deficient shark

21 and ray species. It is important to derive some insight into the status of these species, both to

22 understand global extinction rates and also to ensure that any threatened Data Deficient species

23 are not overlooked in conservation planning. Here, we developed a biological and ecological trait

24 model to predict the categorical conservation status of 26 Northeast Atlantic and 15

25 Mediterranean Sea Data Deficient sharks and rays. We first developed an explanatory model

26 based on all species evaluated on the International Union for Conservation of Nature (IUCN)

27 Red List of Threatened Species ${ }^{\mathrm{TM}}$, using maximum body size, median depth (as a proxy for

28 fisheries exposure), and reproductive mode, and then predicted the status of all Data Deficient

29 species. Almost half of Northeast Atlantic (46\%, $n=12$ of 26), and two-thirds of Mediterranean

$30(67 \%, n=10$ of 15) Data Deficient species are predicted to be in one of the three IUCN threatened

31 categories. Northeast Atlantic Data Deficient species are predicted to be 1.2 times more

32 threatened than evaluated species (38\%, $n=36$ of 94), whereas threat levels in the Mediterranean

33 Sea are relative for each $(66 \%, n=38$ of 58$)$. This case study is intended for extrapolation to the

34 global shark and ray dataset upon completion of the global IUCN Red List assessment. Trait-

35 based, categorical prediction of conservation status is a cost-effective approach towards

36 incorporating Data Deficient species into (i) estimates of lineage-wide extinction rates, (ii)

37 revised protected species lists, and (iii) Red List Indices, thus preventing poorly known species

38 from reaching extinction unnoticed. 


\section{INTRODUCTION}

40 Despite a broadening of coverage of species and more intensive Red List assessment by the

41 International Union for Conservation of Nature (IUCN) in the past decade, over one-sixth or

42 around 13,465 species have been found to be Data Deficient (Bland et al., 2017). Data-deficiency

43 is most prevalent in reptiles and amphibians, marine and freshwater organisms, invertebrates,

44 and plants (Bland et al., 2012, 2014; Böhm et al., 2013; Callmander et al., 2005; Collen et al.,

45 2012; Hoffmann et al., 2010). The IUCN classification means that there are insufficient data to

46 make a more refined determination, hence Data Deficient species could range from actually

47 being Least Concern or they could be threatened or even Extinct. Data-deficiency creates

48 uncertainty in estimates of extinction rates, which is a key challenge to track progress towards

49 the Convention on Biological Diversity's (CBD) Aichi Target 12: to halt the loss of biodiversity

50 by 2020 (CBD \& UNEP, 2011). Clearly, a complete understanding of which species are

51 threatened (Vulnerable, Endangered, or Critically Endangered) is an essential first step toward

52 tracking and improving species's status (Bland et al., 2014, 2015).

54 Data Deficient species are typically overlooked in conservation planning (Bland et al., 2014),

55 with the implicit assumption that the biology and threatening processes of both Data Deficient

56 and data-sufficient species are similar. To provide a first-approximation of the extinction rate of

57 any taxon, the IUCN assumes Data Deficient species are equally as threatened as the data-

58 sufficient species within a taxonomic group (Hoffmann et al., 2010). However, there are

59 numerous reasons why the trait distribution and exposure to threatening processes might be

60 different. For example, most recently discovered sharks have been found in the deep sea

61 (Randhawa et al., 2015) and are relatively small-bodied, beyond the reach of most fisheries, 
62 hence those Data Deficient deepwater species may actually be Least Concern because they have

63 refuge from the main threatening process of overfishing. Conversely, many recently resolved

64 species complexes, such as devil rays, eagle rays, and skates may be highly exposed to fisheries

65 and hence the newly described 'Data Deficient' species might already be highly threatened

66 (Iglésias et al., 2010; White \& Last, 2012).

67

68 There is a vast body of work on the correlates of population trajectories and extinction risk

69 (Cardillo et al., 2005; McKinney, 1997; Owens \& Bennett, 2000). Broadly, large body size,

70 small geographic range, and ecological specialisation are the biological traits most often related

71 to extinction risk, depending on their interaction with the appropriate threatening process (Owens

72 \& Bennett, 2000; Reynolds et al., 2005b). Only recently has this knowledge been used to predict

73 extinction risk of Data Deficient species (Bland et al., 2015; Butchart \& Bird, 2010; Dulvy et al.,

74 2014; Jetz \& Freckleton, 2015). Trait-based predictions of IUCN conservation status use

75 biological and ecological trait data to predict the most likely categorisations for Data Deficient

76 species based on assessed species. The simplest approach is to make the binary prediction

77 whether a Data Deficient species is Least Concern or threatened. This approach has been used

78 with a high degree of accuracy for mammals, birds, sharks and rays (Bland et al., 2015; Butchart

79 \& Bird, 2010; Dulvy et al., 2014; Jetz \& Freckleton, 2015). The most significant advance has

80 been the development of ordinal (or categorical) regression which enables prediction of the

81 actual IUCN Red List category, based on relevant biological and ecological traits (Luiz et al.,

82 2016). A total of 50 of 163 groupers (family Epinephelinae) were Data Deficient, yet trait-based

83 ordinal regression revealed a total of three species predicted to be Critically Endangered, five to

84 be Endangered, and 12 to be Vulnerable (Luiz et al., 2016). 
86 Sharks and rays represent the oldest evolutionary radiation of vertebrate Classes (Stein et al.,

87 2018), with an incredibly broad range of life-histories, spanning all ocean basins, and down to

88 great depths (Cortés, 2000; Dulvy et al., 2014; Dulvy \& Forrest, 2010). This makes them ideal

89 for trait-based predictive modelling, while their high levels of population-relevant data-

90 deficiency present the opportunity to test categorical predictions on a highly Data Deficient

91 group for the first time. Europe represents the first region to be reassessed as part of an ongoing

92 global IUCN Red List reassessment of sharks and rays, as well as being one of the most

93 relatively data-sufficient regions for the Class (Dulvy et al., 2016; Fernandes et al., 2017; Nieto

94 et al., 2015).

95

96 Here, we use Europe's sharks and rays to consider three questions: (1) which biological and

97 ecological traits are driving extinction risk; (2) how does the proportion of evaluated-threatened

98 species compare with predicted-to-be-threatened Data Deficient species; and (3) which are the

99 most threatened Data Deficient sharks and rays? We used cumulative link mixed-effects

100 modeling (CLMM) to evaluate the relationship between species' trait data and conservation

101 status, and eventually predict the conservation status of Europe's Data Deficient sharks and rays.

102 This CLMM approach maintains the hierarchy of the IUCN categories while preventing the loss

103 of information inevitable from lumping categories together as threatened and non-threatened

104 (Luiz et al., 2016). Model performance was evaluated using the Akaike Information Criterion

105 (AIC) with small sample size correction $\left(\mathrm{AIC}_{\mathrm{c}}\right)$. 


\section{METHODS}

109 First, we describe the IUCN Red List conservation assessment of European sharks and rays.

110 Second, we describe the development of an explanatory trait-based model to explain

111 conservation status. Third, we describe the prediction and cross-validation of the conservation

112 status of Europe's Data Deficient sharks and rays.

$114 \quad 2.1$ IUCN Red List assessment

115 The European Red List assessments spanned the Northeast Atlantic Ocean and the

116 Mediterranean and Black Seas, including the territorial waters and Exclusive Economic Zones of

117 all European countries in the Northeast and Eastern Central Atlantic Ocean, and the offshore

118 Macronesian island territories belonging to Portugal and Spain (Dulvy et al., 2016; Fernandes et

119 al., 2017; Nieto et al., 2015).

121 In total, 131 species were assessed at the regional level for Europe using the 2001 IUCN Red

122 List Categories and Criteria, version 3.1 (IUCN, 2012b). We convened 54 experts, composed

123 mainly of members of the IUCN Shark Specialist Group, and completed the 131 European

124 assessments over 21 months, from 2013-15. This culminated in a one-week workshop, attended

125 by fifteen IUCN Shark Specialist Group members, to finalise and review all assessments. The

126 assessed species included 50 skates and rays (Order Rajiformes), 72 sharks (Order

127 Carcharhiniformes, Hexanchiformes, Lamniformes, Squaliformes, Squatiniformes), and nine

128 chimaeras (Order Chimaeriformes). Only breeding residents of Europe were included in the

129 assessments, including 'visitor' species defined by the IUCN as "a taxon that does not reproduce

130 within a region but regularly occurs within its boundaries either now or during some period of 
131 the last century" (IUCN, 2012a). The only visitors in Europe are currently the Smalltooth

132 Sawfish (Pristis pristis, Linnaeus 1758), and Largetooth Sawfish (Pristis pectinata, Latham

133 1794). Vagrant species were not included in assessments, which by IUCN definition are "a taxon

134 that is currently found only occasionally within the boundaries of a region". Vagrant species

135 previously listed in Europe were listed as Not Applicable, and discounted from the following

136 analyses (e.g., the Nurse Shark, Ginglymostoma cirratum, Bonnaterre 1788; Nieto et al., 2015).

137 The IUCN Red List categories considered in this assessment are Least Concern, Near

138 Threatened, Vulnerable, Endangered, Critically Endangered, and Data Deficient, as there are no

139 sharks or rays known to be Regionally Extinct from the entire European region at present. This

140 ordering represents lowest to highest extinction risk, with the exception of Data Deficient, which

141 could include species that are both low and high risk.

\section{$143 \quad 2.2$ Developing an explanatory trait-based model for conservation status}

144 We considered three biological and ecological traits: maximum body size, median depth, and

145 reproductive mode (Dulvy \& Forrest, 2010; Dulvy \& Reynolds, 2002; Field et al., 2009; Rigby

146 \& Simpfendorfer, 2015). Large maximum body size has been related to a greater likelihood of

147 decline and extinction risk due to higher catchability and slower population growth rates in

148 fishes, and other vertebrates (Dillingham et al., 2016; Field et al., 2009; Pardo et al., 2016).

149 Deeper depth ranges are associated with refuge from fishing activity, and hence, lower extinction

150 risk (Dulvy et al., 2014; Luiz et al., 2016). Overfishing is the greatest threat to sharks and rays

151 and occurs predominantly down to $400 \mathrm{~m}$ deep and exceptionally down to greater depths (Bailey

152 et al., 2009). Egg-laying (oviparous) species tend to be more fecund than live-bearing

153 (viviparous) species and hence may have greater maximum population growth rates, greater 
154 variance in reproductive output, and hence scope for density-dependent compensation and lower

155 sensitivity to fishing mortality for adults (Dulvy \& Forrest, 2010; Forrest et al., 2008).

157 There are inherent differences in biogeography, fisheries, and fisheries management between

158 Europe's major sub-regions, the Northeast Atlantic Ocean and Mediterranean Sea, which

159 warranted building models separately for each. There are 120 Northeast Atlantic sharks and rays

160 and 73 Mediterranean species, so lumping the two together as a Europe-wide status created a

161 bias towards Northeast Atlantic status. The IUCN categories were scored as Least Concern $=0$,

162 Near Threatened $=1$, Vulnerable $=2$, Endangered $=3$, and Critically Endangered $=4($ Butchart

163 et al., 2007). For each sub-regional model, IUCN category was the response variable and

164 maximum body size (cm, total length), median depth $(\mathrm{m})$, reproductive mode (scored oviparous

$165=1$ or viviparous $=0$ ). Median depth was used as a proxy for minimum depth and depth range to

166 account for exclusively shallow or deep species' distributions, while also avoiding having two

167 highly correlated fixed effects within a model. We also considered the interaction between size

168 and depth as a fixed effect. The interaction between size and depth is important because large-

169 bodied species are only associated with higher extinction risk if they exist within the reach of

170 fisheries (Dulvy et al., 2014). Size and depth were centred and scaled by two standard deviations.

171 Family was included as a random effect to account for phylogenetic covariation.

172

\section{$173 \quad 2.3$ Predicting conservation status}

174 Predictive accuracy of the explanatory model was evaluated using Area Under the Curve (AUC)

175 from Receiver Operating Characteristic curves (Sing et al., 2005). The AUC measure only works

176 for binary classification, so to test the predictive accuracy of each of the five categories 
177 individually we scored each of the five IUCN categories separately as one, against all four other

178 categories scored as zero. We also grouped the threatened categories (Critically Endangered,

179 Endangered, Vulnerable) with a score of one, and non-threatened (Near Threatened, Least

180 Concern) scored as zero to determine the model accuracy for predicting threatened versus non-

181 threatened species. Predictive power was tested using data-sufficient species by dropping species

182 from the model to predict the conservation status and cross-validate against each known,

183 assessed conservation status. Test sets were run, comprising all data-sufficient species with all

184 species dropped one at a time. The model for each sub-region that was able to predict the correct

185 IUCN status with the highest AUC predictive accuracy measure was then used to predict the

186 categories of the actual Data Deficient species. The highest overall accuracy for a model was

187 determined by calculating the mean across all five AUC values for each IUCN category. Finally,

188 the IUCN categorisation for each Data Deficient species was classified using a 50\% cut-off

189 point. All analyses were conducted in R version 3.5.2 (R Core Team, 2018), models were fit

190 using the clmm2 function from the ordinal package (Christensen, 2019), and performance was

191 evaluated with the ROCR package, version 1.0-7 (Sing et al., 2005).

1943 RESULTS

$195 \quad 3.1$ IUCN regional European Red List assessment

196 One-fifth of the 120 Northeast Atlantic (22\%,n=26) and 73 Mediterranean Sea $(21 \%, n=15)$

197 shark and ray species assessed in 2015 are listed as Data Deficient (Figure 1, Table 1). Most

198 species are assessed as Least Concern (38\%) in the Northeast Atlantic, whereas the majority of

199 species are Critically Endangered (27\%) in the Mediterranean Sea (Figure 1). Specifically, of the 
204 Critically Endangered (Figure 1, Table 1). Sharks and rays are more threatened in Europe than

205 the global average $(17.4 \%, n=181$; Table 1$)$. Specifically, nearly one-third $(30 \%, n=36)$ are

206 threatened in the Northeast Atlantic and over half $(52 \%, n=38)$ are threatened in the

207 Mediterranean Sea. Rays are approximately as threatened as sharks in both regions, in the

208 Northeast Atlantic 32\% (n=14) of rays are threatened versus 33\% $(n=22)$ of sharks, and in the

209 Mediterranean Sea 50\% $(n=16)$ of rays are threatened versus 55\% $(n=22)$ of sharks (Table 1).

\section{$211 \quad 3.2$ Biological and ecological predictors of conservation status}

212 Large-bodied sharks and rays are more likely to be in higher categories of threat across Europe,

213 particularly in the Mediterranean Sea where threat levels are generally higher (Figure 2a,b).

214 When considering maximum body size in the Northeast Atlantic only, for every one unit increase

215 in maximum body size (i.e. $\mathrm{cm}$ total length), the odds of a species being in an IUCN category of

216 equal or higher threat increase by 0.98 (Figure 3a, Table S1). Similarly, in the Mediterranean

217 Sea, for every one unit increase in maximum body size, the odds of a species being in an IUCN

218 category of equal or higher threat increase by 0.94 (Figure 3a, Table S1). All other things being

219 equal, a shark or ray of three metres total length in the Northeast Atlantic has a 71.7\%

220 probability of being in a threatened category (e.g. the Sandbar Shark, Carcharhinus plumbeus,

221 Nardo 1827) compared to a $1.5 \mathrm{~m}$ species, which has a $39.4 \%$ probability of the same (e.g. the

222 Angular Roughshark, Oxynotus centrina, Linnaeus 1758; Figure 2a). Whereas, in the 
223 Mediterranean Sea the Sandbar Shark is $84.5 \%$ likely to be in a threatened category and the

224 Angular Roughshark is $62.1 \%$ likely to be threatened in this sub-region (Figure 2b). Hence, the

225 conservation status of a 1.5 m shark or ray in the Mediterranean Sea is closer to that of a three

226 metre species in the Northeast Atlantic, showing much less difference in likely conservation

227 status between similar sized species in the Mediterranean Sea.

229 Sharks and rays with greater depth distributions are more likely to be in lower categories of

230 threat in the Northeast Atlantic (Figure 2c), but this pattern is muted in the Mediterranean Sea

231 because threat levels are generally high for species across all depth distributions (Figure 2d).

232 When considering median depth in the Northeast Atlantic only, for every one unit increase in

233 median depth (i.e. metres), the odds of a species being in an IUCN category of higher threat

234 decrease by 0.04 (Figure 3c, Table S1). In the Mediterranean Sea, for every one unit increase in

235 median depth, the odds of a species being in a higher category of threat decrease by 0.24 (Figure

2363 c, Table S1). A similar-sized shark or ray with a median depth of $200 \mathrm{~m}$ has a $60 \%$ chance of

237 being threatened in the Northeast Atlantic (e.g. the Nursehound, Scyliorhinus stellaris, Linnaeus

238 1758), compared with a species with a median depth of 1,000 m (e.g. the Blackmouth Catshark,

239 Galeus melastomus, Rafinesque 1810), which has a $21.5 \%$ chance of being threatened in the

240 same sub-region (Figure 2c). In the Mediterranean Sea the difference in risk is muted because of

241 the greater reach of fisheries there: the Nursehound is $71.1 \%$ likely to be threatened, while the

242 Blackmouth Catshark is $40.6 \%$ likely to be threatened in this sub-region (Figure 2d). Again,

243 there is less differentiation between shallow and deepwater conservation status for

244 Mediterranean species than Northeast Atlantic, and a higher likelihood of being threatened

245 overall. 
247 When maximum size, median depth, and reproductive mode are all considered, the odds of an

248 egg-laying (oviparous) species being in a higher threat category decrease by 0.14 in the

249 Northeast Atlantic (Figure 3b, Table S1). This effect was not significant in the Mediterranean

250 Sea, again because the trait sensitivity is overridden or muted by the higher degree of exposure to

251 fishing (Figure 3b, Table S1).

252

253 The most at-risk shark and ray species across Europe are therefore larger-bodied species

254 restricted to the most heavily fished 0-400 $\mathrm{m}$ depth zone. The interaction between size and depth

255 is such that for every unit increase in both size $(\mathrm{cm})$ and depth $(\mathrm{m})$, the odds of a shark or ray

256 being in a higher category of threat decrease by 0.02 in the Northeast Atlantic, and by 0.05 in the

257 Mediterranean Sea (Figure 3d, Table S1).

$259 \quad 3.3$ Predicted versus evaluated conservation status

260 The model with highest predictive accuracy (AUC) for both European sub-regions includes body

261 size, reproductive mode, and the interaction between size and depth (Table 2, Figure 3). For the

262 Northeast Atlantic, more than eight times out of ten, the top model predicts the correct category

263 for the Critically Endangered, Endangered, Least Concern, or grouped threatened categories

264 (Table S2). The Vulnerable category is predicted correctly more than six times out of ten, and the

265 Near Threatened less than four times out of ten. The top model for the Mediterranean Sea

266 predicts the Least Concern category correctly more than eight times out of then, and the

267 Critically Endangered and Near Threatened categories more than seven times out of ten. Both

268 sub-regional top models are weaker at predicting mid-range categories, with the Endangered 
category predicted correctly less than five times and the Vulnerable category less than six times

270 out of ten (Table S2).

271

272 Almost half of Northeast Atlantic, and two-thirds of Mediterranean Data Deficient sharks and

273 rays are predicted-to-be-threatened with an elevated risk of extinction (Figure 4c). This

274 percentage of predicted threatened sharks and rays is greater than evaluated threat levels in the

275 Northeast Atlantic (46\% predicted versus $38 \%$ evaluated threatened), and similar to evaluated

276 threatened in the Mediterranean Sea (67\% predicted versus 66\% evaluated threatened). The 12

277 Northeast Atlantic species predicted-to-be-threatened comprise 11 sharks and one ray (Figure

278 4a). All 12 Northeast Atlantic predicted-to-be-threatened species range from 89-640 cm total

279 length, with depth ranges overlapping with fishing activity, and are viviparous. The ten

280 predicted-to-be-threatened Mediterranean species comprise nine sharks and one ray (Figure 4b,

281 Table S3). All nine species range from 114-427 $\mathrm{cm}$ total length, overlap significantly with the

282 heavily fished depth zone, and are viviparous.

284 The distribution of both evaluated and predicted Northeast Atlantic listings in each case shows a

285 median categorisation of Near Threatened, whereas in the Mediterranean Sea the median

286 categorisation for both is Endangered (Figure S1). Overall, Northeast Atlantic and Mediterranean

287 Sea listings have opposing distributions, with the majority of Northeast Atlantic species non-

288 threatened and the majority of Mediterranean species threatened (Figure S1). 
291 The species predicted to have the most elevated extinction risk (i.e. Critically Endangered)

292 across Europe are all viviparous, large-bodied (349-640 cm total length) sharks whose median

293 depths range from 40.5-350 m, hence overlapping greatly with the heavily fished zone (0-400 m

294 depth; Table S3). In the Northeast Atlantic, the Great White Shark (Carcharodon carcharias,

295 Linnaeus 1758) and Great Hammerhead Shark (Sphyrna mokarran, Rüppell 1837) are predicted

296 to be Critically Endangered (Figure 4a; Table S3). While in the Mediterranean Sea, the Dusky

297 Shark (Carcharhinus obscurus, Lesueur 1818), Copper Shark (Carcharhinus brachyurus,

298 Günther 1870), and Longfin Mako (Isurus paucus, Guitart 1966) are predicted to be Critically

299 Endangered (Figure 4b; Table S3). With this categorical regression approach, we identify a total

300 of 14 Critically Endangered species in the Northeast Atlantic (approximately one third of

301 threatened) and 23 Critically Endangered species in the Mediterranean Sea (approximately one

302 half of threatened; Figure 5). If conservation efforts were focused on all imperilled species, i.e.

303 the combined evaluated-threatened and predicted-to-be-threatened species, there would be a

304 target list of 48 species to protect in the Northeast Atlantic and 48 species in the Mediterranean

305 Sea (Table 3, Figure 5).

306

307

3084 DISCUSSION

$309 \quad 4.1$ Regional versus global IUCN Red List Status

310 Here, we show that sharks and rays are proportionally more threatened in the two main sub-

311 regions of Europe than the global reported threat rate, particularly when we account for the

312 predicted risk status of Data Deficient species. Overall, we estimate that there are 40\% (48)

313 imperilled species (evaluated threatened and predicted-to-be-threatened) in the Northeast 
314 Atlantic and 67\% (48) in the Mediterranean Sea. Compared with other vertebrate groups, these

315 threat levels not only exceed those of global sharks and rays (23.9\%, $n=249$ of 1,041, (Dulvy et

316 al., 2014), but also that of amphibians: the most imperilled assessed group to date $(41 \%, n=2,561$

317 of 6,284, Hoffmann et al., 2010). Furthermore, whereas almost half of global sharks and rays are

318 Data Deficient $(46.8 \%, n=487)$, approximately one-fifth of Europe's species are Data Deficient,

319 which is also closer to global amphibian data deficiency proportionally $(26 \%, n=1,597$;

320 Hoffmann et al., 2010). The high levels of threat and relatively low levels of data deficiency in

321 Europe result from the region's comparably long-standing history of fishing and data collection

322 compared with the rest of the world (Barrett et al., 2004; Hoffmann, 1996). We next consider: (1)

323 the biological and ecological traits driving these regional threat levels, (2) the differences

324 between evaluated and predicted conservation status, and (3) how categorically predicting such

325 could help narrow the focus of conservation efforts overall.

\subsection{Biological and ecological predictors of conservation status}

328 Sharks and rays with both larger maximum body size and shallower depth distribution are more

329 likely to face an elevated risk of extinction than smaller (faster-growing) species that live

330 predominantly in deeper water. Fishing is the greatest threat to sharks and rays (McClenachan, et

331 al., 2012), and it is greatest from 0-400 m depth, but in European waters lower levels of fishing

332 activity occur down to at least 1,000 m (Amoroso et al., 2018; Morato et al., 2006). In waters

333 deeper than the reach of fisheries, a species can be very large-bodied and not threatened at all,

334 because body size has little influence over conservation status unless it is combined with a major

335 threat (Fernandes et al., 2017; Owens \& Bennett, 2000; Reynolds et al., 2005a). For example, the

336 Goblin Shark (Mitsukurina owstoni, Jordan 1898) reaches $617 \mathrm{~cm}$ total length with a depth range 
of 40-1,569 m. This deepwater shark is listed as Least Concern in the Northeast Atlantic as the

338 majority of its depth range offers refuge from fishing activity. By contrast, the Common

339 Thresher Shark (Alopias vulpinus, Bonnaterre 1788) reaches $573 \mathrm{~cm}$ total length, has a depth

340 range of 0-366 m (i.e. entirely overlapping with the heavily fished zone), and is listed as

341 Endangered in the same sub-region. Large body size has been associated with increased

342 probability of extinction for numerous taxonomic groups (e.g. Cardillo et al., 2011; Comeros-

343 Raynal et al., 2016; Field et al., 2009). Large body size is known to be correlated to a slow

344 speed-of-life, but also as an impediment to evading capture in fishing gear. For shark and ray

345 conservation, accounting for this relationship between size and susceptibility to capture is

346 complicated by the issue of bycatch. More sharks and rays are threatened by incidental catch

347 than by actual target fisheries (Dulvy et al., 2014), where their higher intrinsic sensitivity is not

348 accounted for by fisheries management regimes that are focused on faster growing, less sensitive

349 teleost (bony fish) species. Across Europe, the predominant fishing techniques are highly

350 unselective, such as multi-species trawling (Smith \& Garcia, 2014). The incentive for fishers to

351 increase selectivity to benefit non-target species is low when this action would undoubtedly

352 coincide with reduced target catch. The consequent unselective fishing of non-target species is a

353 major driver of the high threat levels among Europe's sharks and rays and could lead to

354 overlooked local extinctions. This predicament alone presents incentive to better understand the

355 status of Data Deficient species, particularly in heavily fished waters such as Europe.

357 The conservation status of sharks and rays in the Mediterranean Sea appears much worse than

358 the Northeast Atlantic, which can partly be explained by the lack of depth refuge for sharks and

359 rays from heavy fishing activity in this sub-region. The Mediterranean Sea has a longer history 
360 of fishing than the Northeast Atlantic, and nowadays, that fishing is not managed as efficiently as

361 it is in the Northeast Atlantic (Fernandes et al., 2017; Smith \& Garcia, 2014). A semi-enclosed

362 sea equates to many more sites for landing catches, none of which are being consistently

363 monitored. Further exacerbating this lack of monitoring, the Mediterranean fishery principally

364 comprises higher numbers of smaller artisanal vessels, compared with fewer, more readily

365 trackable commercial vessels in the Northeast Atlantic (Smith \& Garcia, 2014). Semi-enclosed

366 seas are also more susceptible to other major threatening events than open oceans, such as ocean

367 acidification, rising temperatures, and coastal pollution and development (Caddy, 2000). Despite

368 these logical contributors to the higher threat levels seen among Mediterranean sharks and rays,

369 the difference in conservation status between both major European sub-regions can largely be

370 attributed to the differing taxonomic and hence trait composition (120 Northeast Atlantic and 73

371 Mediterranean Sea sharks and rays). There are 35 deepwater shark and ray species that exist in

372 the Northeast Atlantic exclusively outside the reach of fisheries, and are all therefore listed as

373 Least Concern, which do not occur in the Mediterranean Sea. If those species are removed from

374 the Northeast Atlantic species list, we see the same number of imperilled species in each sub-

375 region, and a much more similar overall proportion of threat (Table S4). Meanwhile, the median

376 depths of all 73 Mediterranean Sea species overlap to some degree (if not entirely) with the

377 heavily fished 0-400 m depth zone. This explains why median depth, and the interaction

378 between maximum body size and median depth, are weaker explanatory variables in this sub-

379 region: depth refuge from fishing activity simply does not exist for sharks and rays in the

380 Mediterranean Sea. 
382 Perhaps the prevailing threat resultant from lacking refuge in the Mediterranean Sea also

383 explains to some extent why oviparous species are not significantly lower-risk in this sub-region

384 than viviparous species. Oviparity is characteristically associated with faster population growth

385 rates than viviparity (Field et al., 2009). All of the most threatened sharks and rays in Europe are

386 viviparous, likely because they are less able to withstand fishing pressure as effectively as

387 typically faster-growing, egg-laying species.

\subsection{Predicted versus evaluated conservation status}

390 To provide taxon-wide estimates of extinction risk in the face of uncertainty, the IUCN assumes

391 that the fraction of threatened Data Deficient species is the same as the proportion of evaluated-

392 threatened species. While pragmatic, this is an assumption to be tested. A recent estimate of

393 which Data Deficient sharks and rays might be classified as Least Concern or threatened

394 revealed 14\% of Data Deficient species were predicted-to-be-threatened ( $n=68$ of 487$)$, and

395 overall $17.8 \%$ were evaluated-threatened (Dulvy et al., 2014). Taken together, there is an overall

396 estimated global threat level of 23.9\% imperilled sharks and rays (Dulvy et al., 2014). By

397 comparison, this is much lower than the IUCN equal ratio approach, which hence yields an

398 inflated estimate of $33 \%$ of sharks and rays threatened (Hoffmann et al., 2010).

400 This 1:1 ratio of predicted-to-evaluated threatened species proportions holds true for global birds

401 (Class Aves), in which knowledge is significantly greater than for other taxa and hence there are

402 few Data Deficient species $(0.6 \%, n=63$ of 10 500; Butchart \& Bird, 2010). This 1:1 ratio

403 approach, however, yields a 50\% underestimation of globally Data Deficient threatened

404 mammals, where one-third of evaluated species are threatened, whereas two-thirds of Data 
Deficient species are predicted-to-be-threatened (1:2, Jetz \& Freckleton, 2015). In the case of

406

407

408

409

410

411

412

413

414

415

416

417

\subsection{Updating protected species lists in Europe}

There are a number of lists that flag species for protection, but many of these are now out-of-

427 listed on the Oslo-Paris convention in the Northeast Atlantic (Table 3). While of the 48 
428 imperilled species identified here in the Mediterranean Sea, only three (and five) are listed on

429 Appendix II (and Appendix III) of the Berne Convention, nine on Appendix III of the Barcelona

430 Convention, and 23 on the General Fisheries Commission for the Mediterranean priority species

431 list (Table 3). The Great Hammerhead Shark is currently one of the 24 species included on the

432 GFCM priority species list for the Mediterranean Sea, but since the 2015 European Red List

433 reassessment this species is considered a Vagrant in this basin. We therefore consider only 23

434 species on the GFCM priority species list in this study (Table 3). Clearly, there is significant

435 scope to update these lists to ensure protection of all imperilled species in both sub-regions.

$437 \quad 4.5$ Incorporating predictions into a Red List Index for 2020 target tracking

438 Categorical predictions of IUCN status enable the inclusion of Data Deficient species in

439 aggregate species conservation status analyses, from which they are currently excluded for all

440 taxonomic groups. The Convention on Biological Diversity's Aichi Targets are monitored using

441 indicators, such as the IUCN's Red List Index, which is an indicator of the change in aggregate

442 extinction risk over time (Brooks et al., 2015). Predicting IUCN status for Data Deficient species

443 enables their addition to such indices, which would in turn give conservation planners a more

444 holistic idea of conservation status. With sufficient model accuracy, it is likely more informative

445 to include these predictions in such indices than to exclude them altogether. Upon completion of

446 the ongoing global reassessment of sharks and rays, this methodology can be extrapolated to the

447 global dataset for inclusion in the global Red List Index. This approach would prove even more

448 accurate for highly data-sufficient groups such as birds. Resource limitations have hindered

449 scientists and conservationists from focusing on Data Deficient species historically, but

450 categorical predictions of conservation status are a cost-effective solution to this shortcoming 
451 (Bland et al., 2015), at least until data availability and resources allow for fully comprehensive

452 IUCN assessment of these species. This case study, and the extrapolation to the highly Data

453 Deficient global shark and ray dataset, will ideally be the first step towards applying this

454 predictive approach to some more Data Deficient groups, such as plants and invertebrates.

457 ACKNOWLEDGEMENTS

458 We thank the IUCN Species Survival Commission Shark Specialist Group members, staff, and

459 volunteers, and the IUCN head office for their logistical support throughout the Red List

460 assessment process. In particular, we thank Alvaro Abella, David Allen, Michel Bariche, Tom

461 Blasdale, Mohamed N Bradaï, Elena Buscher, Maurice Clarke, Simona Clo, Andrey Dolgov,

462 Manuel Dureuil, Jim Ellis, Edward Farrell, Francesco Ferretti, Sonia Fordham, Sarah Fowler,

463 Karen Frazer, Mariana García, Javier Guallart, Lucy Harrison, Ali Hood, Samuel Iglésias,

464 Armelle Jung, James Kemp, Pete Kyne, Julia Lawson, Sophy McCully, Ana Nieto, Giuseppe

465 Notarbartolo di Sciara, Caroline Pollock, Gina Ralph, Fabrizio Serena, Bernard Seret, Alen

466 Soldo, Matthias Stehmann, Heike Zidowitz. We thank Tobias Sing, Dan Greenberg, Nathan

467 Pacoureau, Chris Brown, and Rylee Murray for statistical advice, and members of the Dulvy

468 Lab, Earth ${ }_{2}$ Ocean Lab and Stats Beerz for comment on drafts and statistical advice.

470 Funding: The European Red List of marine fishes was a project funded by the European

471 Commission (Directorate General for the Environment under Service Contract No.

$472070307 / 2011 / 607526 /$ SER/B.3). This project was funded by the Shark Conservation Fund as part

473 of the Global Shark Trends Project. Rachel Walls and Nicholas Dulvy were supported by a 
474 Natural Science and Engineering Research Council Discovery and Accelerator Award and

475 Nicholas Dulvy was supported by the Canada Research Chairs Program. Rachel Walls was also

476 supported by Simon Fraser University with three Graduate Fellowship awards.

477

478

\section{REFERENCES}

480

481

482

483

484

485

486

487

488

489

490

491

492

493

494

495

496
Amoroso, R. O., Pitcher, C. R., Rijnsdorp, A. D., McConnaughey, R. A., Parma, A. M., Suuronen, P., ... Jennings, S. (2018). Bottom trawl fishing footprints on the world's continental shelves. Proceedings of the National Academy of Sciences, 115(43), E10275E10282. http://doi.org/10.1073/pnas.1802379115

Bailey, D. M., Collins, M. A., Gordon, J. D. M., Zuur, A. F., \& Priede, I. G. (2009). Long-term changes in deep-water fish populations in the northeast Atlantic: A deeper reaching effect of fisheries? Proceedings of the Royal Society B: Biological Sciences, 276(1664), 1965-1969. http://doi.org/10.1098/rspb.2009.0098

Barrett, J. H., Locker, A. M., \& Roberts, C. M. (2004). The origins of intensive marine fishing in medieval Europe: the English evidence. Proceedings of the Royal Society B: Biological Sciences, 271, 2417-2421. http://doi.org/10.1098/rspb.2004.2885

Bland, L. M., Bielby, J., Kearney, S., Orme, C. D. L., Watson, J. E. M., \& Collen, B. (2017). Toward reassessing data-deficient species. Conservation Biology, 31(3), 531-539. http://doi.org/10.1111/cobi.12850

Bland, L. M., \& Böhm, M. (2016). Overcoming data deficiency in reptiles. Biological Conservation, 204, 16-22. http://doi.org/10.1016/j.biocon.2016.05.018

Bland, L. M., Collen, B., Orme, C. D. L., \& Bielby, J. (2012). Data uncertainty and the 
selectivity of extinction risk in freshwater invertebrates. Diversity and Distributions, 18(12), 1211-1220. http://doi.org/10.1111/j.1472-4642.2012.00914.x

Bland, L. M., Collen, B., Orme, C. D. L., \& Bielby, J. (2014). Predicting the conservation status of data-deficient species. Conservation Biology, 29(1), 250-259. http://doi.org/10.1111/cobi.12372

Bland, L. M., Collen, B., Orme, C. D. L., \& Bielby, J. (2015). Predicting the conservation status of data-deficient species. Conservation Biology, 29(1), 250-259. http://doi.org/10.1111/cobi.12372

Bland, L. M., Orme, C. D. L., Bielby, J., Collen, B., Nicholson, E., \& Mccarthy, M. A. (2015). Cost-effective assessment of extinction risk with limited information. Journal of Applied Ecology, 52(4), 861-870. http://doi.org/10.1111/1365-2664.12459

Böhm, M., Collen, B., Baillie, J. E. M., Bowles, P., Chanson, J., Cox, N., ... Zug, G. (2013). The conservation status of the world's reptiles. Biological Conservation, 157, 372-385.

Brooks, T. M., Butchart, S. H. M., Cox, N. A., Heath, M., Hilton-Taylor, C., Hoffmann, M., ... Smart, J. (2015). Harnessing biodiversity and conservation knowledge products to track the

515 Butchart, S. H. M., Akçakaya, H. R., Chanson, J., Baillie, J. E. M., Collen, B., Quader, S., ...

516 Hilton-Taylor, C. (2007). Improvements to the Red List Index. PLoS ONE, 2(1).

517 http://doi.org/10.1371/journal.pone.0000140

518 Butchart, S. H. M., \& Bird, J. P. (2010). Data Deficient birds on the IUCN Red List: What don’t 519 we know and why does it matter? Biological Conservation, 143(1), 239-247. 
http://doi.org/10.1016/j.biocon.2009.10.008

521 Caddy, J. (2000). Marine catchment basin effects versus impacts of fisheries on semi-enclosed

522 seas. ICES Journal of Marine Science, 57(3), 628-640.

523 http://doi.org/10.1006/jmsc.2000.0739

524 Callmander, M. W., Schatz, G. E., \& Lowry, P. P. (2005). IUCN Red List assessment and the

525 Global Strategy for Plant Conservation: Taxonomists must act now. Taxon, 54(4), 10471050. http://doi.org/10.2307/25065491

527 Cardillo, M., Mace, G., Jones, K. E., Bielby, J., Bininda-Emonds, O. R. P., Sechrest, W., ...

528 Purvis, A. (2005). Multiple causes of high extinction risk in large mammal species. Science, $529 \quad 309(5738), 1239-1241$.

530 Cardillo, M., Mace, G. M., Jones, K. E., Bielby, J., Bininda-emonds, O. R. P., \& Sechrest, W. 531 (2011). Multiple Causes of High Extinction Risk in Large Mammal Species. Science, 532 1239(2005), 1239-1241. http://doi.org/10.1126/science.1116030

533 CBD, \& UNEP. (2011). The Strategic Plan for Biodiversity 2011-2020 and the Aichi Targets

534 "Living in Harmony with Nature." A Ten-Year Framework for Action by All Countries and

535 Stakeholders to Save Biodiversity and Enhance Its Benefits for People. Secretariat of the

$536 \quad$ Convention, 2. Retrieved from www.cbd.int

537 Christensen, R. H. B. (2019). Package ‘ordinal.' Retrieved from https://cran.r-

$538 \quad$ project.org/web/packages/ordinal/ordinal.pdf

539 Collen, B., Böhm, M., Kemp, R., \& Baillie, J. E. M. (2012). Spineless: status and trends of the $540 \quad$ world's invertebrates. London, United Kingdom.

541 Comeros-Raynal, M. T., Polidoro, B. A., Broatch, J., Mann, B. Q., Gorman, C., Buxton, C. D., $542 \quad$... Carpenter, K. E. (2016). Key predictors of extinction risk in sea breams and porgies 
(Family: Sparidae). Biological Conservation, 202, 88-98.

http://doi.org/10.1016/j.biocon.2016.08.027

545 Cortés, E. (2000). Life history patterns and correlations in sharks. Reviews in Fisheries Science, $546 \quad 8(4), 299-344$.

547 Dillingham, P. W., Moore, J. E., Fletcher, D., Cortés, E., Alexandra Curtis, K., James, K. C., \&

548 Lewison, R. L. (2016). Improved estimation of intrinsic growth rmax for long-lived species:

549 Integrating matrix models and allometry. Ecological Applications, 26(1), 322-333.

$550 \quad$ http://doi.org/10.1890/14-1990

551 Dulvy, N., Allen, D., Ralph, G., \& Walls, R. (2016). The conservation status of Sharks, Rays and 552 in the Mediterranean Sea., 6+6 pp.

553 Dulvy, N., \& Forrest, R. (2010). Life histories, population dynamics, and extinction risks in 554 chondrichthyans. In J. Carrier, J. Musick, \& M. Heithaus (Eds.), Sharks and Their Relatives 555 II: Biodiversity, Adaptive Physiology, and Conservation (pp. 635-676). CRC Press: Boca

$556 \quad$ Raton.

557 Dulvy, N. K., \& Forrest, R. E. (2010). Biodiversity, adapative physiology, and conservation. In J.

558 C. Carrier, J. A. Musick, \& M. R. Heithaus (Eds.), Sharks and their relatives II (pp. 640559 670). Boca Raton, FL: CRC Press.

560 Dulvy, N. K., Fowler, S. L., Musick, J. A., Cavanagh, R. D., Kyne, P. M., Harrison, L. R., ...

561 White, W. T. (2014). Extinction risk and conservation of the world's sharks and rays. ELife, 562 3. http://doi.org/10.7554/eLife.00590

563 Dulvy, N. K., \& Reynolds, J. D. (2002). Predicting extinction vulnerability in skates.

564 Conservation Biology, 16(2), 440-450. http://doi.org/10.1046/j.1523-1739.2002.00416.x

565 Fernandes, P. G., Ralph, G. M., Nieto, A., García Criado, M., Vasilakopoulos, P., Maravelias, C. 
D., ... Carpenter, K. E. (2017). Coherent assessments of Europe's marine fishes show regional divergence and megafauna loss. Nature Ecology \& Evolution, 1(May), 0170. http://doi.org/10.1038/s41559-017-0170

569 Field IC, Meekan M, Buckworth RC, \& Bradshaw CJA. (2009). Susceptibility of Sharks, Rays and Chimeras to Global Extinction. Advances in Marine Biology (1st ed., Vol. 56). Elsevier Ltd. http://doi.org/10.1016/S0065-2881(09)56004-X

572 Forrest, R. E., Martell, S. J. D., Melnychuk, M. C., \& Walters, C. J. (2008). An age-structured model with leading management parameters, incorporating age-specific selectivity and

Hoffmann, M., Hilton-taylor, C., Angulo, A., Böhm, M., Brooks, T. M., Butchart, S. H. M., ... maturity. Canadian Journal of Fisheries and Aquatic Sciences, 65(2), 286-296.

Hoffmann, R. C. (1996). Economic Development and Aquatic Ecosystems in Medieval Europe. American Historical Review, 101, 631-669. http://doi.org/10.4324/9781315252094-5

581 Iglésias, S. P., Toulhoat, L., \& Sellos, D. Y. (2010). Taxonomic confusion and market Russell, A. (2010). The Impact of Conservation on the Status of the World's Vertebrates.

IUCN. (2012a). Guidelines for application of IUCN Red List criteria at regional and national levels: Version 4.0 (4th ed.). Gland, Switzerland and Cambridge, UK: IUCN, Gland, Switzerland. Retrieved from www.iucn.org/publications

588 IUCN. (2012b). IUCN Red List Categories and Criteria: version 3.1. (IUCN, Ed.) (Second). 
Gland, Switzerland and Cambridge, UK: IUCN, Gland, Switzerland. http://doi.org/https://www.iucnredlist.org/static/categories_criteria_3_1

591 Jetz, W., \& Freckleton, R. P. (2015). Towards a general framework for predicting threat status of 592 data-deficient species from phylogenetic, spatial and environmental information. Philosophical Transactions of the Royal Society of London. Series B, Biological Sciences, 370(1662), 20140016. http://doi.org/10.1098/rstb.2014.0016

Luiz, O. J., Woods, R. M., Madin, E. M. P., \& Madin, J. S. (2016). Predicting IUCN Extinction Risk Categories for the World's Data Deficient Groupers (Teleostei: Epinephelidae).

McClenachan, L., Cooper, A. B., Carpenter, K. E., \& Dulvy, N. K. (2012). Extinction risk and bottlenecks in the conservation of charismatic marine species. Conservation Letters, 5(1), 73-80. http://doi.org/10.1111/j.1755-263X.2011.00206.X

604 Morato, T., Watson, R., Pitcher, T. J., \& Pauly, D. (2006). Fishing down the deep, 23-33. 605 Nieto, a., Ralph, G. M., Comeros-Raynal, M. T., Kemp, J., García Criado, M., Allen, D. J., ... 606 Williams, J. T. (2015). European Red List of Marine Fishes, 88. http://doi.org/10.2779/082723

608 Owens, I. P. F., \& Bennett, P. M. (2000). Ecological basis of extinction risk in birds $\square$ : Habitat 609 loss versus human persecution and introduced predators. PNAS, 97(22), 12144-12148.

610 Pardo, S. A., Kindsvater, H. K., Cuevas-Zimbrón, E., Sosa-Nishizaki, O., Pérez-Jiménez, J. C., 611 \& Dulvy, N. K. (2016). Growth, productivity, and relative extinction risk of a data-sparse 
devil ray. Scientific Reports, 6, 1-10. http://doi.org/10.1038/srep33745

613 Randhawa, H. S., Poulin, R., \& Krkošek, M. (2015). Increasing rate of species discovery in

614 sharks coincides with sharp population declines: Implications for biodiversity. Ecography,

615 38(1), 96-107. http://doi.org/10.1111/ecog.00793

616 Reynolds, J. D., Webb, T. J., \& Hawkins, L. A. (2005a). Life history and ecological correlates of

617 extinction risk in European freshwater fishes. Canadian Journal of Fisheries and Aquatic

618 Sciences, 62(4), 854-862. http://doi.org/10.1139/f05-066

619 Reynolds, J. D., Webb, T. J., \& Hawkins, L. A. (2005b). Life history and ecological correlates of

620 extinction risk in European freshwater fishes 1, 862(August 2003), 854-862.

621 http://doi.org/10.1139/F05-066

622 Rigby, C., \& Simpfendorfer, C. A. (2015). Patterns in life history traits of deep-water

623 chondrichthyans. Deep-Sea Research Part II: Topical Studies in Oceanography, 115, 30-

624 40. http://doi.org/10.1016/j.dsr2.2013.09.004

625 Sing, T., Sander, O., Beerenwinkel, N., \& Lengauer, T. (2005). ROCR: Visualizing classifier

626 performance in R. Bioinformatics, 21(20), 3940-3941.

627 http://doi.org/10.1093/bioinformatics/bti623

628 Smith, A. D. M., \& Garcia, S. M. (2014). Fishery management: Contrasts in the mediterranean

629 and the atlantic. Current Biology, 24(17), R810-R812.

630 http://doi.org/10.1016/j.cub.2014.07.031

631 Stein, R. W., Mull, C. G., Kuhn, T. S., Aschliman, N. C., Davidson, L. N. K., Joy, J. B., ...

632 Mooers, A. O. (2018). Global priorities for conserving the evolutionary history of sharks,

633 rays and chimaeras. Nature Ecology and Evolution, 2(February), 1-11.

$634 \quad$ http://doi.org/10.1038/s41559-017-0448-4 

aCC-BY 4.0 International license.

635 White, W. T., \& Last, P. R. (2012). A review of the taxonomy of chondrichthyan fishes: a

636 modern perspective. Journal of Fish Biology, 80(5), 901-917. http://doi.org/10.1111/j.1095-

$637 \quad$ 8649.2011.03192.x

638 
TABLES LEGENDS

640

Table 1

641 Global and European IUCN Red Listings of sharks and rays. Observed number and (percent)

642 of global (2014), Northeast Atlantic (2015), and Mediterranean Sea (2015) sharks, rays (i.e. all

643 rays and skates), and chimaeras in each IUCN Red List category. CR: Critically Endangered,

644 EN: Endangered, VU: Vulnerable, thr: threatened (CR+EN+VU), NT: Near Threatened, LC:

645 Least Concern, DD: Data Deficient (*Dulvy et al., 2014).

646

Table 2

648 Summary of top Cumulative Link Mixed-effects Models for predicting IUCN status of

649 Northeast Atlantic and Mediterranean sharks and rays. Models included all evaluated

650 species ( $n=94$ Northeast Atlantic and $n=58$ Mediterranean Sea). Top predictive models for both

651 sub-regions with $\triangle \mathrm{AIC}<2$ included maximum size $(\mathrm{cm})$, reproductive mode (oviparous=1,

652 viviparous $=0$ ), and the interaction between maximum size and median depth (m). Maximum size

653 and median depth were centred and standardised by two standard deviations. Each species was

654 dropped one-at-a-time from the model and the IUCN status predicted. Comparison between

655 evaluated and predicted statuses determined the predictive accuracy of each model. Model

656 accuracy was measured as the Area Under the Curve (AUC) from the ROCR package in R

657 version 3.5.2 (Sing et al., 2005) by scoring each category as one and all four other categories as

658 zero to determine the predictive accuracy of all five separately (Critically Endangered,

659 Endangered, Vulnerable, Near Threatened, Least Concern). To determine the top predictive

660 model overall, the mean of all five category AUC values was calculated. Left to right: Loglik =

$661 \log$ likelihood, $\mathrm{AIC}_{\mathrm{c}}=\mathrm{AIC}$ corrected for small sample size, $\triangle \mathrm{AIC}=$ delta $\mathrm{AIC}, \mathrm{AIC}$ wt $=\mathrm{AIC}$ 
662 weight, mean AUC $=$ Area Under Curve averaged across the five AUC values for each IUCN

663 category (see Table S2 for complete list of AUC values).

\section{Table 3}

666 Current consideration of all imperilled sharks and rays in European waters by regional

667 conventions and priority species lists. Relevant listings of all imperilled (i.e. evaluated-

668 threatened and predicted-to-be-threatened) sharks and rays in Europe on regional and global

669 protection-focused conventions, by major sub-region (Northeast Atlantic then Mediterranean

670 Sea). Blanks indicate no listing, while hyphens indicate inapplicability of a convention to a

671 species within a certain sub-region. Where a convention has multiple appendices, the applicable

672 appendix number is indicated (e.g. A2, A3) instead of a tick mark. Species are listed

673 taxonomically within each threatened IUCN category - Critically Endangered (CR), Endangered

$674(\mathrm{EN})$, and Vulnerable (VU) - in descending order of threat. Conventions left to right: Oslo-Paris

675 Convention (OSPAR; applicable to Northeast Atlantic Ocean only); Berne Convention

676 (applicable to Mediterranean Sea only); Barcelona Convention (Mediterranean Sea only); and

677 the General Fisheries Commission for the Mediterranean (GFCM) priority species list

678 (Mediterranean Sea only). The Great Hammerhead Shark (Sphyrna mokarran) is currently one of

67924 species included on the GFCM priority species list, but has not been included in the

680 Mediterranean section of this table as it is now considered a Vagrant species in the

681 Mediterranean Sea, as per IUCN definition (IUCN, 2012a). 
FIGURE LEGENDS

\section{Figure 1}

684 Percent evaluated and predicted IUCN categorisations of Europe's sharks and rays. Dark

685 bars represent the percentage of species officially evaluated on the IUCN Red List, while light

686 bars represent the percentage of Data Deficient species predicted to be under each category as

687 per the results of the present study. Of the 120 species in the Northeast Atlantic, 94 were

688 evaluated and 26 were Data Deficient and predicted for. In the Mediterranean Sea, 58 of 73

689 species were evaluated and 15 were Data Deficient and predicted for. The IUCN categories from

690 highest to lowest threat are: $\mathrm{CR}=$ Critically Endangered, EN = Endangered, VU = Vulnerable,

691 NT $=$ Near Threatened, and LC $=$ Least Concern.

Figure 2

694 The effects of size and depth on shark and ray conservation status in Europe. Histograms of

695 the probability of an evaluated shark or ray being listed as either Critically Endangered (CR),

696 Endangered (EN), Vulnerable (VU), Near Threatened (NT), or Least Concern (LC) based on

697 single-trait Cumulative Link Mixed-effects Model outputs for maximum body size (cm; panels a

698 and b) and median depth (m; panels c and d). Data include all evaluated species ( $n=94$ Northeast

699 Atlantic, panels a and c; and $n=58$ Mediterranean Sea, panels b and d) and exclude all Data

700 Deficient species. Dark grey vertical bars indicate large (300 cm total length, a,b) or shallow

701 (200 m median depth, c,d) species; light grey bars represent small (150 cm total length, a,b) or

702 deep (1,000 m median depth, c,d) species. Brackets beside bars indicate the probability of each

703 species being categorised as threatened (CR, EN, or VU) on the IUCN Red List. 


\section{Figure 3}

706 Effects of biological and ecological traits on Europe's shark and ray conservation status.

707 Standardized effect sizes with $95 \%$ confidence intervals. Cumulative link mixed effect models

708 with maximum body size (a), reproductive mode (b), median depth (c), and the interaction

709 between size and depth (d) as fixed effects and taxonomic Family as a random effect to account

710 for phylogenetic non-independence. Circular and triangular points represent the best explanatory

711 and predictive model for the Northeast Atlantic and Mediterranean Sea, respectively, which in

712 both cases included maximum body size, reproductive mode, and the interaction between

713 maximum size and median depth. Data for maximum size and median depth were centred and

714 standardised by two standard deviations, while reproductive mode is a binary trait where

715 oviparous species $=1$ and viviparous species $=0$.

\section{Figure 4}

718 Predicted and evaluated conservation status of Europe's sharks and rays. Top Cumulative

719 Link Mixed-effectd Models including maximum body size, reproductive mode, and the

720 interaction between size and median depth as fixed effects (for both sub-regions) and taxonomic

721 Family as a random effect to account for phylogenetic non-independence. Panel a shows the

722 probability of all 26 Data Deficient Northeast Atlantic species, and panel $b$ of all 15

723 Mediterranean Sea species, being in each IUCN Red List category based on these top

724 explanatory models. The vertical line cutting down panels a and b represents the 50\% cut-off

725 classification used to assign the final IUCN categorisations (according to the category bar the

726 line crosses). Data for size and depth were centred and standardised by two standard deviations,

727 while reproductive mode is a binary trait where oviparous species $=1$ and viviparous species $=0$. 
728 Panel c shows the proportion of sharks and rays in the Northeast Atlantic (left) and

729 Mediterranean Sea (right) both evaluated and predicted to be in each IUCN category. Percentage

730 values within each yellow bar indicate the total percentage of evaluated threatened and

731 predicted-to-be-threatened species in each set, while numbers within brackets below each bar

732 indicate the total number of species included in each set

733

734 Figure 5

735 Informing shark and ray conservation efforts in Europe with categorical predictions. Solid

736 grey bars represent species of all IUCN categories excluding those officially evaluated by the

737 IUCN as Critically Endangered (CR), which are represented by solid red blocks. There are 120

738 shark and ray species in the Northeast Atlantic (left) and 73 in the Mediterranean Sea (right).

739 Horizontal red lines indicate the addition of all Data Deficient species predicted to be Critically

740 Endangered, to the evaluated block. Orange lines indicate all evaluated and predicted-to-be-

741 Endangered and Critically Endangered species, while yellow lines show all imperilled (i.e.

742 evaluated and predicted-to-be-threatened) species (Vulnerable, Endangered, and Critically

743 Endangered). Numbers beside bars indicate total number of species within each relevant

744 grouping. 
Global and European IUCN Red Listings of sharks and rays. Observed number and (percent) of global (2014), Northeast Atlantic

748 (2015), and Mediterranean Sea (2015) sharks, rays (i.e. all rays and skates), and chimaeras in each IUCN Red List category. CR:

749 Critically Endangered, EN: Endangered, VU: Vulnerable, thr: threatened (CR+EN+VU), NT: Near Threatened, LC: Least Concern,

750 DD: Data Deficient (*Dulvy et al., 2014).

\begin{tabular}{|c|c|c|c|c|c|c|c|c|}
\hline Geographic scope & $\begin{array}{l}\text { Total } \\
\text { species }\end{array}$ & $\begin{array}{l}\text { Total thr } \\
\text { species } \\
(\%)\end{array}$ & $\begin{array}{l}\text { Total CR } \\
(\%)\end{array}$ & $\begin{array}{l}\text { Total EN } \\
(\%)\end{array}$ & $\begin{array}{l}\text { Total VU } \\
(\%)\end{array}$ & $\begin{array}{l}\text { Total NT } \\
(\%)\end{array}$ & $\begin{array}{l}\text { Total LC } \\
(\%)\end{array}$ & $\begin{array}{l}\text { Total DD } \\
(\%)\end{array}$ \\
\hline All global* & 1,041 & 181(17) & $25(2)$ & $43(4)$ & $113(11)$ & $132(13)$ & $241(23)$ & $487(47)$ \\
\hline All Northeast Atlantic & 120 & $38(32)$ & $12(10)$ & $15(13)$ & $11(9)$ & $12(10)$ & $48(40)$ & $22(18)$ \\
\hline All Mediterranean Sea & 73 & $39(53)$ & $20(27)$ & $11(15)$ & $8(11)$ & $9(12)$ & $12(17)$ & $13(18)$ \\
\hline Rays (Northeast Atlantic) & 44 & $14(32)$ & $6(14)$ & $3(7)$ & $5(11)$ & $6(14)$ & $22(50)$ & $2(4)$ \\
\hline Sharks (Northeast Atlantic) & 67 & $22(33)$ & $6(9)$ & $12(18)$ & $4(6)$ & $5(7)$ & $16(24)$ & $24(36)$ \\
\hline Chimaeras (Northeast Atlantic) & 9 & - & - & - & - & $1(10)$ & $8(90)$ & - \\
\hline Rays (Mediterranean) & 32 & $16(50)$ & $8(25)$ & $5(16)$ & $3(9)$ & $5(16)$ & $7(22)$ & $4(12)$ \\
\hline Sharks (Mediterranean) & 40 & $22(55)$ & $12(30)$ & $6(15)$ & $4(10)$ & $2(5)$ & $5(12.5)$ & $11(27.5)$ \\
\hline Chimaeras (Mediterranean) & 1 & - & - & - & - & $1(100)$ & - & - \\
\hline
\end{tabular}




\section{Summary of top Cumulative Link Mixed-effects Models for predicting IUCN status of Northeast Atlantic and Mediterranean} models for both sub-regions with $\triangle \mathrm{AIC}<2$ included maximum size $(\mathrm{cm})$, reproductive mode (oviparous=1, viviparous=0), and the interaction between maximum size and median depth (m). Maximum size and median depth were centred and standardised by two standard deviations. Each species was dropped one-at-a-time from the model and the IUCN status predicted. Comparison between evaluated and predicted statuses determined the predictive accuracy of each model. Model accuracy was measured as the Area Under the Curve (AUC) from the ROCR package in R version 3.5.2 (Sing et al., 2005) by scoring each category as one and all four other categories as zero to determine the predictive accuracy of all five separately (Critically Endangered, Endangered, Vulnerable, Near Threatened, Least Concern). To determine the top predictive model overall, the mean of all five category AUC values was calculated.

\begin{tabular}{llccccc}
\hline Region & Model hypothesis & Loglik & AIC $_{c}$ & $\Delta$ AIC & AIC wt & AUC \\
\hline Northeast & IUCN status $~$ & & & & \\
Atlantic & Max size + Reproduction + Max size*Med depth & -91.553 & 201.106 & $5.684 \mathrm{e}-14$ & 0.122 & 0.711 \\
\hline Mediterranean & IUCN status $~$ & -71.528 & 161.055 & 1.833 & 0.066 & 0.657 \\
\hline
\end{tabular}


Table 3

\section{Current consideration of all imperilled sharks and rays in European waters by regional conventions and priority species lists.}

Relevant listings of all imperilled (i.e. evaluated-threatened and predicted-to-be-threatened) sharks and rays in Europe on regional and global protection-focused conventions, by major sub-region (Northeast Atlantic then Mediterranean Sea). Blanks indicate no listing, while hyphens indicate inapplicability of a convention to a species within a certain sub-region. Where a convention has multiple appendices, the applicable appendix number is indicated (e.g. A2, A3) instead of a tick mark. Species are listed taxonomically within each threatened IUCN category - Critically Endangered (CR), Endangered (EN), and Vulnerable (VU) - in descending order of threat. Conventions left to right: Oslo-Paris Convention (OSPAR; applicable to Northeast Atlantic Ocean only); Berne Convention (applicable to Mediterranean Sea only); Barcelona Convention (Mediterranean Sea only); and the General Fisheries Commission for the Mediterranean (GFCM) priority species list (Mediterranean Sea only). The Great Hammerhead Shark (Sphyrna mokarran) is currently one of 24 species included on the GFCM priority species list, but has not been included in the Mediterranean section of this table as it is now considered a Vagrant species in the Mediterranean Sea, as per IUCN definition (IUCN, 2012a).

\begin{tabular}{lllccc}
\hline Species & $\begin{array}{l}\text { Evaluated IUCN } \\
\text { status }\end{array}$ & $\begin{array}{l}\text { Predicted IUCN } \\
\text { status }\end{array}$ & $\begin{array}{l}\text { OSPAR } \\
\text { (NEA) }\end{array}$ & $\begin{array}{l}\text { Berne } \\
\text { Convention } \\
\text { (Med) }\end{array}$ & $\begin{array}{l}\text { Barcelona } \\
\text { Convention } \\
\text { (Med) }\end{array}$ \\
\hline Squatina squatina & Critically Endangered & - & $\begin{array}{l}\text { GFCM } \\
\text { species } \\
\text { (Med) }\end{array}$ \\
\hline Squatina aculeata & Critically Endangered & - & - & - \\
\hline Squatina oculata & Critically Endangered & - & - & - \\
\hline Centrophorus granulosus & Critically Endangered & - & - & - \\
\hline
\end{tabular}




\begin{tabular}{|c|c|c|c|c|c|c|}
\hline Odontaspis ferox & Critically Endangered & - & & - & - & - \\
\hline Lamna nasus & Critically Endangered & - & ? & - & - & - \\
\hline Species & $\begin{array}{l}\text { Evaluated IUCN } \\
\text { status }\end{array}$ & $\begin{array}{l}\text { Predicted IUCN } \\
\text { status }\end{array}$ & $\begin{array}{l}\text { OSPAR } \\
\text { (NEA) }\end{array}$ & $\begin{array}{l}\text { Bern } \\
\text { Convention } \\
\text { (Med) }\end{array}$ & $\begin{array}{l}\text { Barcelona } \\
\text { Convention } \\
\text { (Med) }\end{array}$ & $\begin{array}{l}\text { GFCM } \\
\text { priority } \\
\text { species } \\
\text { (Med) }\end{array}$ \\
\hline Carcharodon carcharias & Data Deficient & Critically Endangered & & - & - & - \\
\hline Sphyrna mokarran & Data Deficient & Critically Endangered & & - & - & - \\
\hline Rostroraja alba & Critically Endangered & - & ? & - & - & - \\
\hline Dipturus batis & Critically Endangered & - & ? & - & - & - \\
\hline Pristis pristis & Critically Endangered & - & & - & - & - \\
\hline Pristis pectinata & Critically Endangered & - & & - & - & - \\
\hline Gymnura altavela & Critically Endangered & - & & - & - & - \\
\hline Pteromylaeus bovinus & Critically Endangered & - & & - & - & - \\
\hline Echinorhinus brucus & Endangered & - & & - & - & - \\
\hline Centrophorus lusitanicus & Endangered & - & & - & - & - \\
\hline Centrophorus squamosus & Endangered & - & ? & - & - & - \\
\hline Deania calcea & Endangered & - & & - & - & - \\
\hline Centroscymnus coelolepis & Endangered & - & & - & - & - \\
\hline Dalatias licha & Endangered & - & & - & - & - \\
\hline Squalus acanthias & Endangered & - & ? & - & - & - \\
\hline Alopias vulpinus & Endangered & - & & - & - & - \\
\hline Alopias superciliosus & Endangered & - & & - & - & - \\
\hline Cetorhinus maximus & Endangered & - & ? & - & - & - \\
\hline Isurus oxyrinchus & Data Deficient & Endangered & & - & - & - \\
\hline Isurus paucus & Data Deficient & Endangered & & - & - & - \\
\hline Galeocerdo cuvier & Data Deficient & Endangered & & - & - & - \\
\hline Sphyrna zygaena & Data Deficient & Endangered & & - & - & - \\
\hline Sphyrna lewini & Data Deficient & Endangered & & - & - & - \\
\hline Carcharhinus plumbeus & Endangered & - & & - & - & - \\
\hline Carcharhinus longimanus & Endangered & - & & - & - & - \\
\hline Carcharhinus obscurus & Data Deficient & Endangered & & - & - & - \\
\hline
\end{tabular}




\begin{tabular}{|c|c|c|c|c|c|c|}
\hline Carcharhinus falciformis & Data Deficient & Endangered & & - & - & - \\
\hline Glaucostegus cemiculus & Endangered & - & & - & - & - \\
\hline Rhinobatos rhinobatos & Endangered & - & & - & - & - \\
\hline Species & $\begin{array}{l}\text { Evaluated IUCN } \\
\text { status }\end{array}$ & $\begin{array}{l}\text { Predicted IUCN } \\
\text { status }\end{array}$ & $\begin{array}{l}\text { OSPAR } \\
\text { (NEA) }\end{array}$ & $\begin{array}{l}\text { Bern } \\
\text { Convention } \\
\text { (Med) }\end{array}$ & $\begin{array}{l}\text { Barcelona } \\
\text { Convention } \\
\text { (Med) }\end{array}$ & $\begin{array}{l}\text { GFCM } \\
\text { priority } \\
\text { species } \\
\text { (Med) }\end{array}$ \\
\hline Mobula mobular & Endangered & - & & - & - & - \\
\hline Hexanchus nakamurai & Data Deficient & Vulnerable & & - & - & - \\
\hline Centrophorus uyato & Vulnerable & - & & - & - & - \\
\hline Oxynotus centrina & Vulnerable & - & & - & - & - \\
\hline Pseudotriakis microdon & Data Deficient & Vulnerable & & - & - & - \\
\hline Galeorhinus galeus & Vulnerable & - & & - & - & - \\
\hline Mustelus mustelus & Vulnerable & - & & - & - & - \\
\hline Leucoraja circularis & Vulnerable & - & & - & - & - \\
\hline Leucoraja fullonica & Vulnerable & - & & - & - & - \\
\hline Rhinoptera marginata & Data Deficient & Vulnerable & & - & - & - \\
\hline Myliobatis aquila & Vulnerable & - & & - & - & - \\
\hline Dasyatis pastinaca & Vulnerable & - & & - & - & - \\
\hline Dasyatis centroura & Vulnerable & - & & - & - & - \\
\hline Squatina squatina & Critically Endangered & - & - & A3 & & ? \\
\hline Squatina aculeata & Critically Endangered & - & - & & & ? \\
\hline Squatina oculata & Critically Endangered & - & - & & & ? \\
\hline Centrophorus granulosus & Critically Endangered & - & - & & A3 & \\
\hline Oxynotus centrina & Critically Endangered & - & - & & & ? \\
\hline Odontaspis ferox & Critically Endangered & - & - & & & ? \\
\hline Carcharias taurus & Critically Endangered & - & - & & & ? \\
\hline Lamna nasus & Critically Endangered & - & - & A3 & & ? \\
\hline Carcharodon carcharias & Critically Endangered & - & - & $\mathrm{A} 2$ & & ? \\
\hline Isurus oxyrinchus & Critically Endangered & - & - & A3 & & ? \\
\hline Isurus paucus & Data Deficient & Critically Endangered & - & & & \\
\hline Sphyrna zygaena & Critically Endangered & - & - & & & ? \\
\hline
\end{tabular}




\begin{tabular}{|c|c|c|c|c|c|c|}
\hline Carcharhinus brachyurus & Data Deficient & Critically Endangered & - & & & \\
\hline Carcharhinus obscurus & Data Deficient & Critically Endangered & - & & & \\
\hline Prionace glauca & Critically Endangered & - & - & A3 & A3 & \\
\hline Species & $\begin{array}{l}\text { Evaluated IUCN } \\
\text { status }\end{array}$ & $\begin{array}{l}\text { Predicted IUCN } \\
\text { status }\end{array}$ & $\begin{array}{l}\text { OSPAR } \\
\text { (NEA) }\end{array}$ & $\begin{array}{l}\text { Bern } \\
\text { Convention } \\
\text { (Med) }\end{array}$ & $\begin{array}{l}\text { Barcelona } \\
\text { Convention } \\
\text { (Med) }\end{array}$ & $\begin{array}{l}\text { GFCM } \\
\text { priority } \\
\text { species } \\
\text { (Med) }\end{array}$ \\
\hline Leucoraja circularis & Critically Endangered & - & - & & & ? \\
\hline Leucoraja melitensis & Critically Endangered & - & - & & & ? \\
\hline Leucoraja fullonica & Critically Endangered & - & - & & & \\
\hline Dipturus batis & Critically Endangered & - & - & & & ? \\
\hline Pristis pristis & Critically Endangered & - & - & & & ? \\
\hline Pristis pectinata & Critically Endangered & - & - & & & ? \\
\hline Gymnura altavela & Critically Endangered & - & - & & & ? \\
\hline Pteromylaeus bovinus & Critically Endangered & - & - & & & \\
\hline Hexanchus nakamurai & Data Deficient & Endangered & - & & & \\
\hline Echinorhinus brucus & Endangered & - & - & & & \\
\hline Somniosus rostratus & Data Deficient & Endangered & - & & & \\
\hline Squalus acanthias & Endangered & - & - & & A3 & ? \\
\hline Alopias vulpinus & Endangered & - & - & & A3 & \\
\hline Alopias superciliosus & Endangered & - & - & & & \\
\hline Cetorhinus maximus & Endangered & - & - & A2 & & ? \\
\hline Carcharhinus altimus & Data Deficient & Endangered & - & & & \\
\hline Carcharhinus plumbeus & Endangered & - & - & & A3 & \\
\hline Carcharhinus limbatus & Data Deficient & Endangered & - & & & \\
\hline Rostroraja alba & Endangered & - & - & A3 & & ? \\
\hline Raja radula & Endangered & - & - & & & \\
\hline Glaucostegus cemiculus & Endangered & - & - & & & ? \\
\hline Rhinobatos rhinobatos & Endangered & - & - & & & ? \\
\hline Rhinoptera marginata & Data Deficient & Endangered & - & & & \\
\hline Mobula mobular & Endangered & - & - & $\mathrm{A} 2$ & & ? \\
\hline Heptranchias perlo & Data Deficient & Vulnerable & - & & A3 & \\
\hline
\end{tabular}




\begin{tabular}{|c|c|c|c|c|c|c|}
\hline Dalatias licha & Vulnerable & - & - & & & \\
\hline Galeorhinus galeus & Vulnerable & - & & - & - & $?$ \\
\hline Species & $\begin{array}{l}\text { Evaluated IUCN } \\
\text { status }\end{array}$ & $\begin{array}{l}\text { Predicted IUCN } \\
\text { status }\end{array}$ & $\begin{array}{l}\text { OSPAR } \\
\text { (NEA) }\end{array}$ & $\begin{array}{l}\text { Bern } \\
\text { Convention } \\
\text { (Med) }\end{array}$ & $\begin{array}{l}\text { Barcelona } \\
\text { Convention } \\
\text { (Med) }\end{array}$ & $\begin{array}{l}\text { GFCM } \\
\text { priority } \\
\text { species } \\
\text { (Med) }\end{array}$ \\
\hline Mustelus asterias & Vulnerable & - & - & & A3 & \\
\hline Mustelus punctulatus & Data Deficient & Vulnerable & - & & A3 & \\
\hline Mustelus mustelus & Vulnerable & - & - & & A3 & \\
\hline Myliobatis aquila & Vulnerable & - & - & & & \\
\hline Dasyatis pastinaca & Vulnerable & - & - & & & \\
\hline Dasyatis centroura & Vulnerable & - & - & & & \\
\hline
\end{tabular}




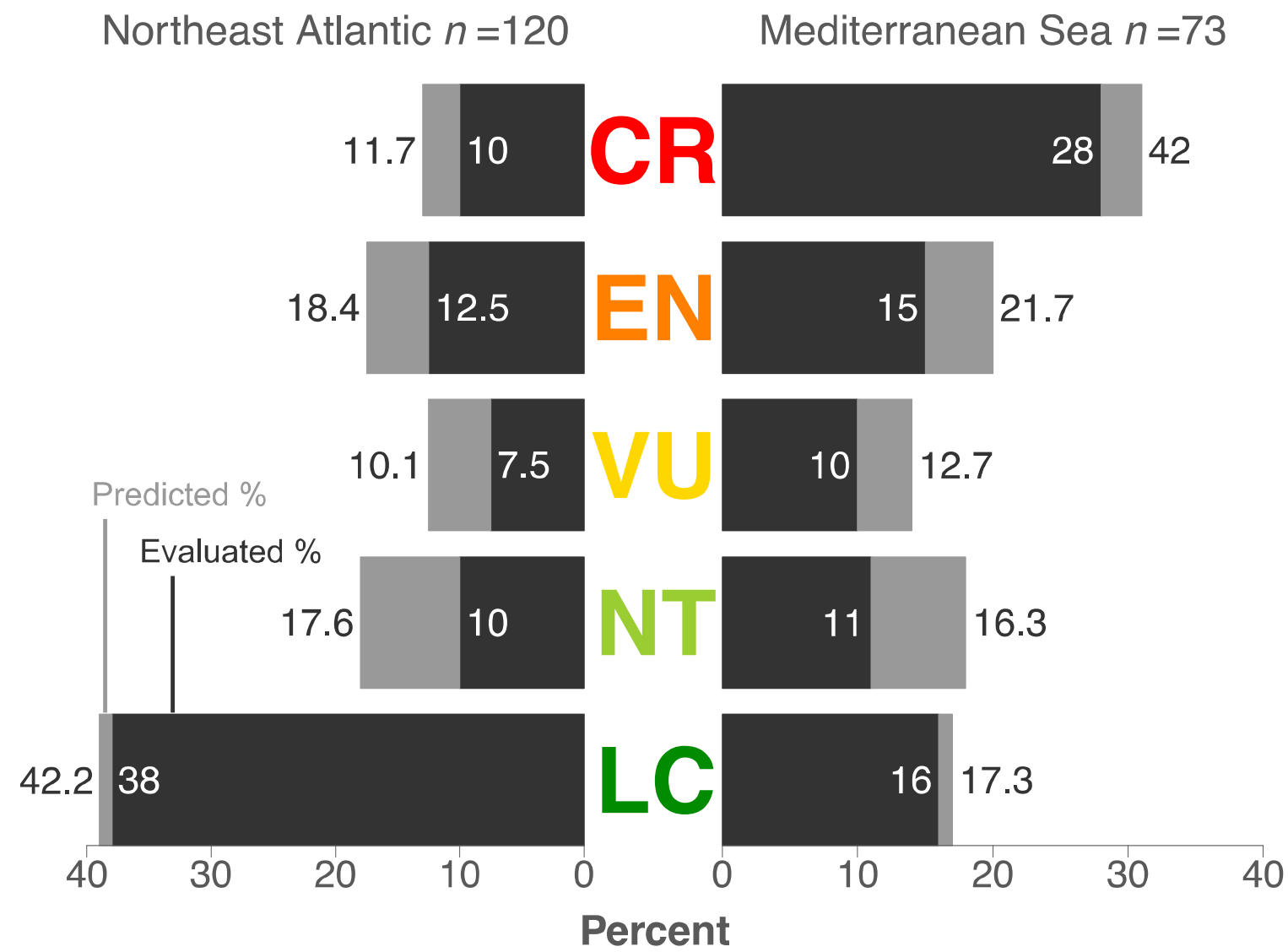

\section{$781 \quad$ Figure 1}

782 Percent evaluated and predicted IUCN categorisations of Europe's sharks and rays. Dark

783 bars represent the percentage of species officially evaluated on the IUCN Red List, while light

784 bars represent the percentage of Data Deficient species predicted to be under each category as

785 per the results of the present study. Of the 120 species in the Northeast Atlantic, 94 were

786 evaluated and 26 were Data Deficient and predicted for. In the Mediterranean Sea, 58 of 73

787 species were evaluated and 15 were Data Deficient and predicted for. The IUCN categories from

788 highest to lowest threat are: $\mathrm{CR}=$ Critically Endangered, $\mathrm{EN}=$ Endangered, $\mathrm{VU}=\mathrm{Vulnerable}$,

$789 \mathrm{NT}=$ Near Threatened, and LC $=$ Least Concern. 


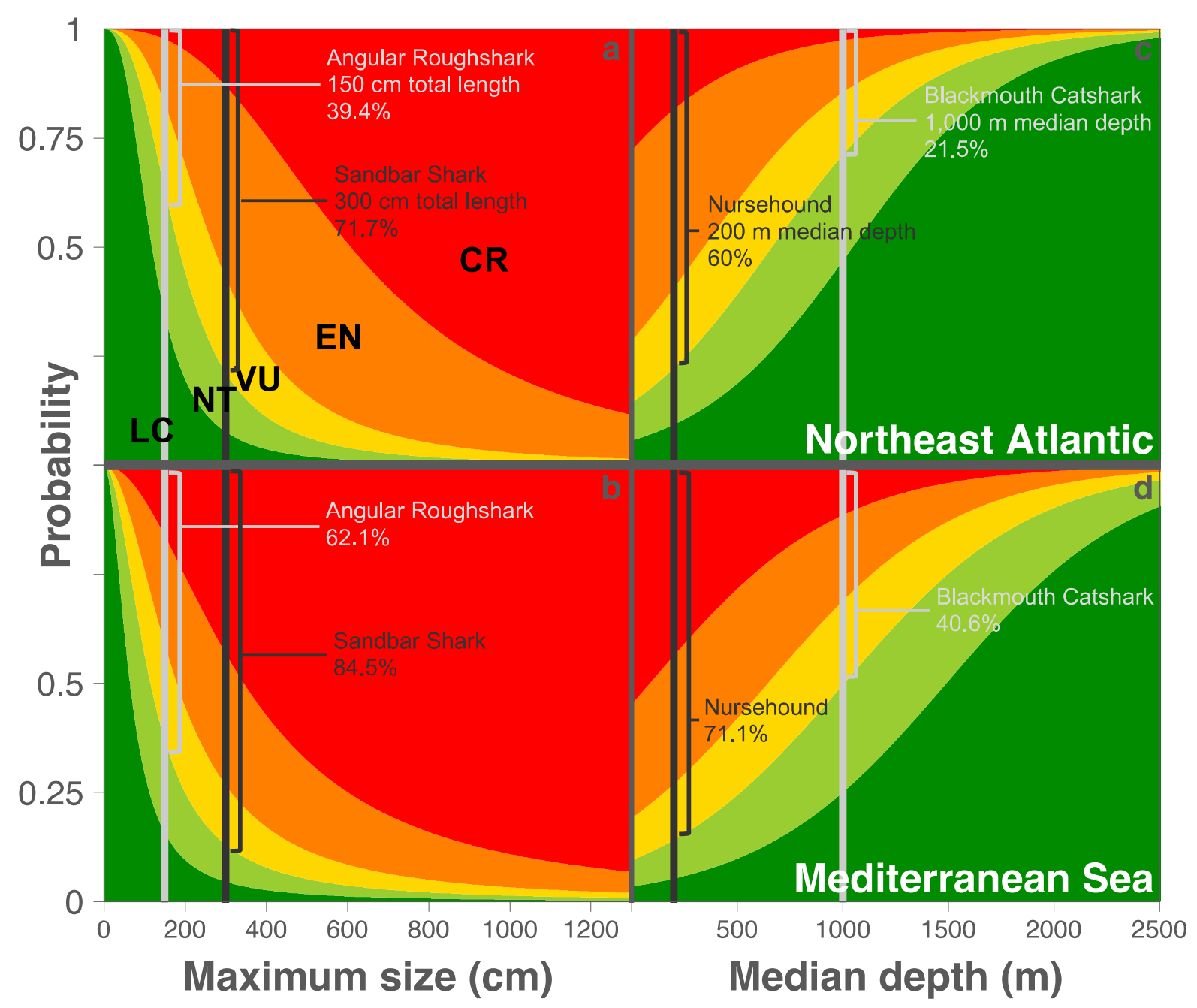

792 Figure 2

793 The effects of size and depth on shark and ray conservation status in Europe. Histograms of

794 the probability of an evaluated shark or ray being listed as either Critically Endangered (CR),

795 Endangered (EN), Vulnerable (VU), Near Threatened (NT), or Least Concern (LC) based on

796 single-trait Cumulative Link Mixed-effects Model outputs for maximum body size (cm; panels a

797 and b) and median depth (m; panels $\mathrm{c}$ and d). Data include all evaluated species ( $n=94$ Northeast

798 Atlantic, panels a and c; and $n=58$ Mediterranean Sea, panels b and d) and exclude all Data

799 Deficient species. Dark grey vertical bars indicate large (300 cm total length, a,b) or shallow

800 (200 m median depth, c,d) species; light grey bars represent small (150 cm total length, a,b) or 
801 deep (1,000 m median depth, c,d) species. Brackets beside bars indicate the probability of each

802 species being categorised as threatened (CR, EN, or VU) on the IUCN Red List.

803

804

805

806

807

808

809

810

811

812

813 


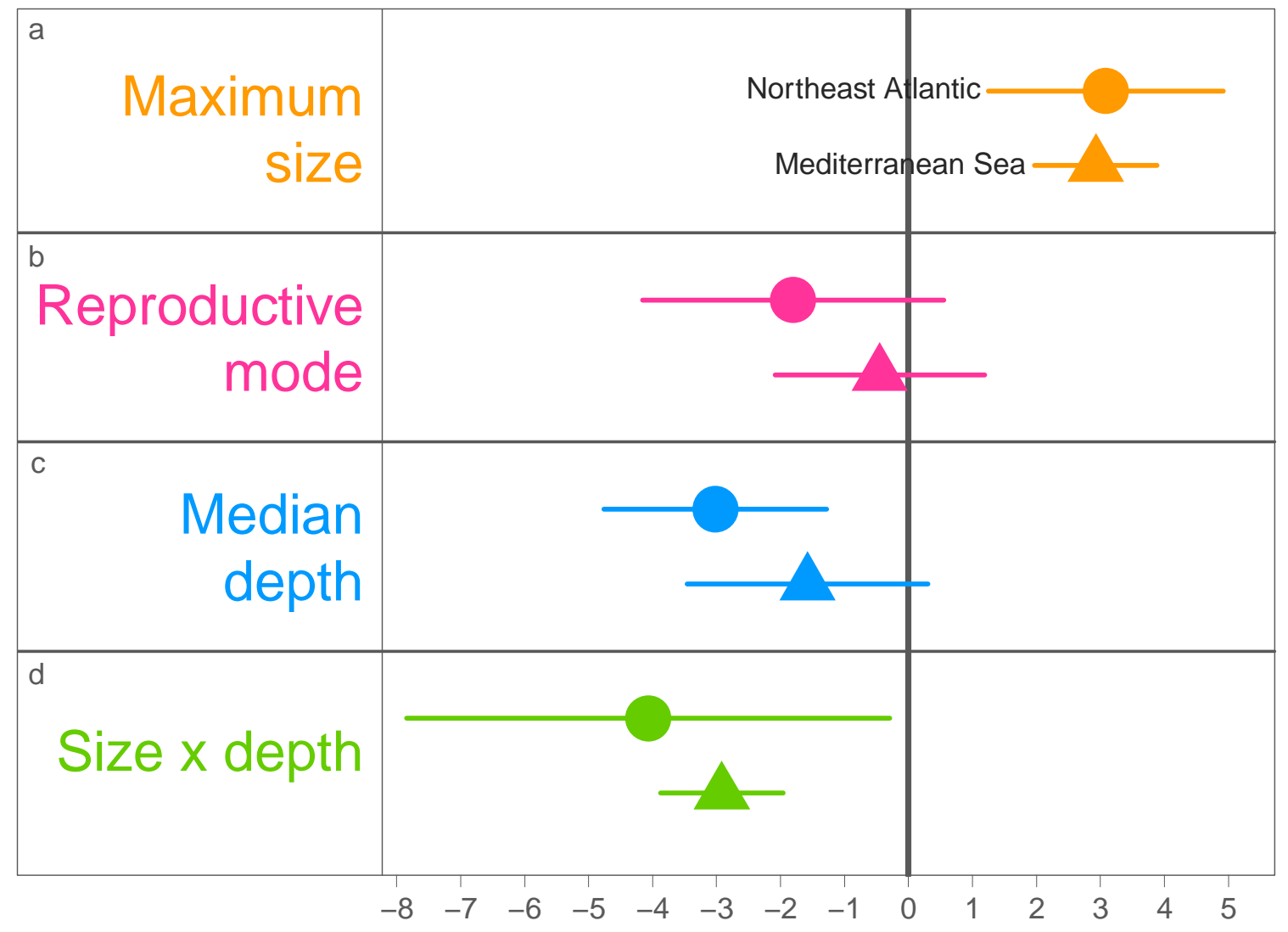

\section{$815 \quad$ Figure 3}

\section{Effects of biological and ecological traits on Europe's shark and ray conservation status.}

817 Standardized effect sizes with $95 \%$ confidence intervals. Cumulative link mixed effect models

818 with maximum body size (a), reproductive mode (b), median depth (c), and the interaction

819 between size and depth (d) as fixed effects and taxonomic Family as a random effect to account

820 for phylogenetic non-independence. Circular and triangular points represent the best explanatory

821 and predictive model for the Northeast Atlantic and Mediterranean Sea, respectively, which in

822 both cases included maximum body size, reproductive mode, and the interaction between

823 maximum size and median depth. Data for maximum size and median depth were centred and

824 standardised by two standard deviations, while reproductive mode is a binary trait where

825 oviparous species $=1$ and viviparous species $=0$. 


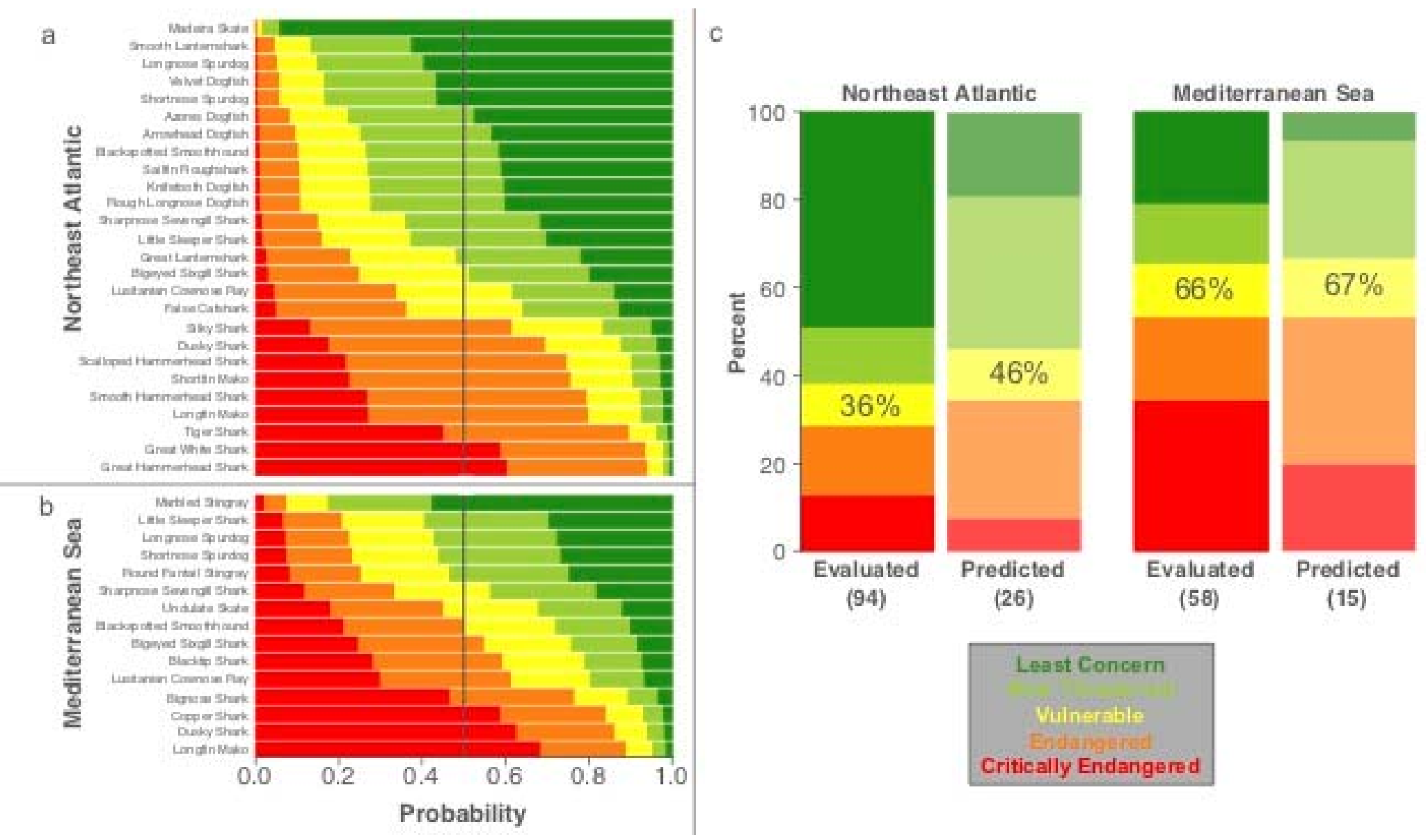

\section{Figure 4}

829 Predicted and evaluated conservation status of Europe's sharks and rays. Top Cumulative Link Mixed-effectd Models including

830 maximum body size, reproductive mode, and the interaction between size and median depth as fixed effects (for both sub-regions) and 
832 Deficient Northeast Atlantic species, and panel b of all 15 Mediterranean Sea species, being in each IUCN Red List category based on

833 these top explanatory models. The vertical line cutting down panels a and b represents the 50\% cut-off classification used to assign the

834 final IUCN categorisations (according to the category bar the line crosses). Data for size and depth were centred and standardised by

835 two standard deviations, while reproductive mode is a binary trait where oviparous species $=1$ and viviparous species $=0$. Panel $\mathrm{c}$

836 shows the proportion of sharks and rays in the Northeast Atlantic (left) and Mediterranean Sea (right) both evaluated and predicted to

837 be in each IUCN category. Percentage values within each yellow bar indicate the total percentage of evaluated threatened and

838 predicted-to-be-threatened species in each set, while numbers within brackets below each bar indicate the total number of species

839 included in each set.

840 


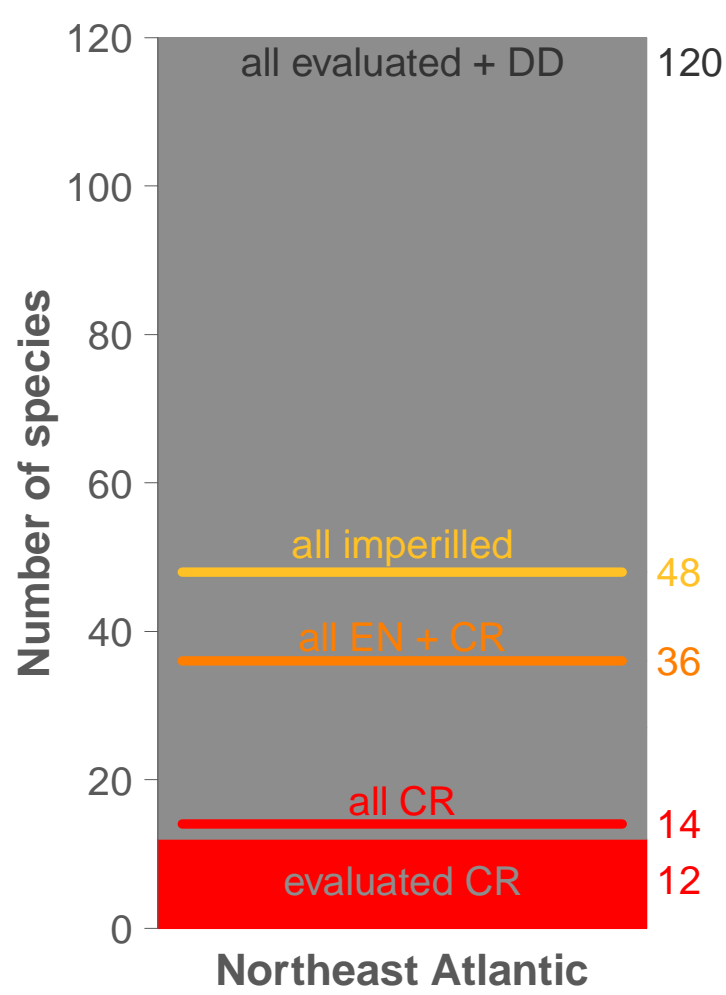

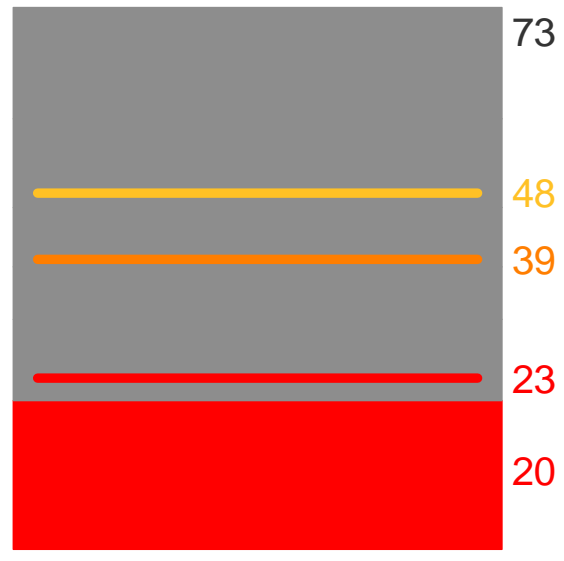

Mediterranean Sea

\section{$842 \quad$ Figure 5}

843 Informing shark and ray conservation efforts in Europe with categorical predictions. Solid

844 grey bars represent species of all IUCN categories excluding those officially evaluated by the

845 IUCN as Critically Endangered (CR), which are represented by solid red blocks. There are 120

846 shark and ray species in the Northeast Atlantic (left) and 73 in the Mediterranean Sea (right).

847 Horizontal red lines indicate the addition of all Data Deficient species predicted to be Critically

848 Endangered, to the evaluated block. Orange lines indicate all evaluated and predicted-to-be-

849 Endangered and Critically Endangered species, while yellow lines show all imperilled (i.e.

850 evaluated and predicted-to-be-threatened) species (Vulnerable, Endangered, and Critically

851 Endangered). Numbers beside bars indicate total number of species within each relevant

852 grouping. 


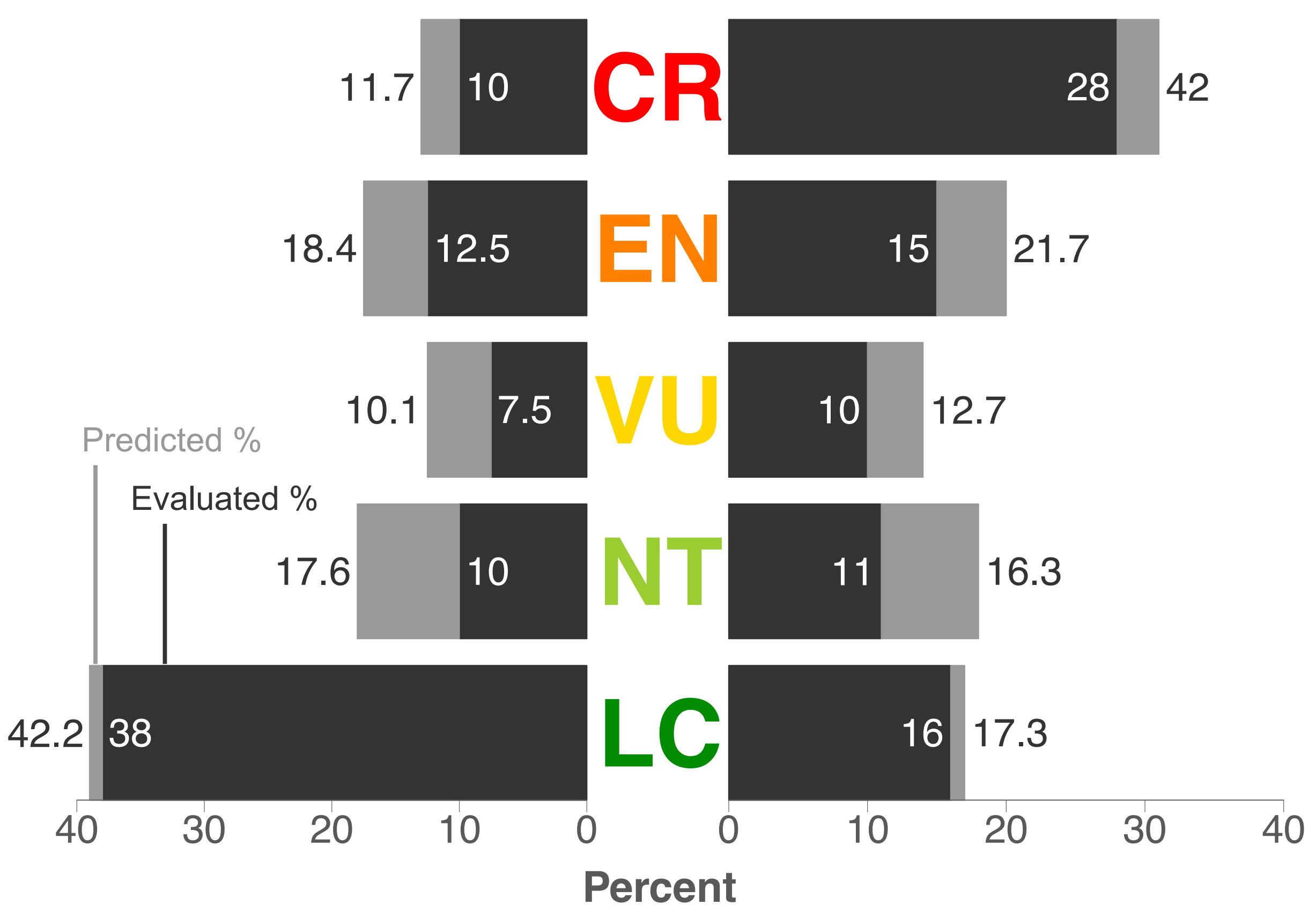



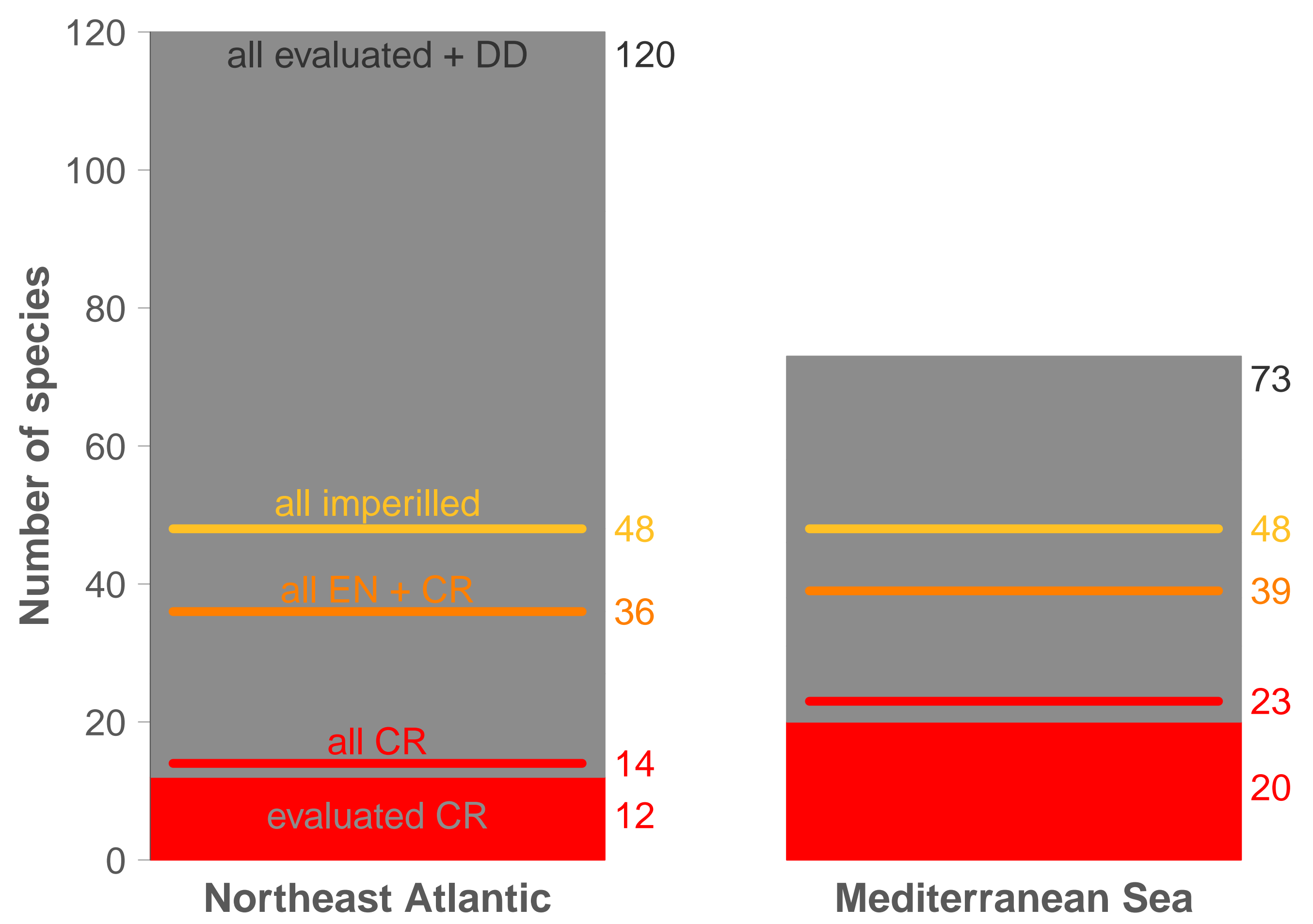

Mediterranean Sea 
Smooth Lanternshark

Longnose Spurdog

Vhortnose Spurdog

Azores Dogfish
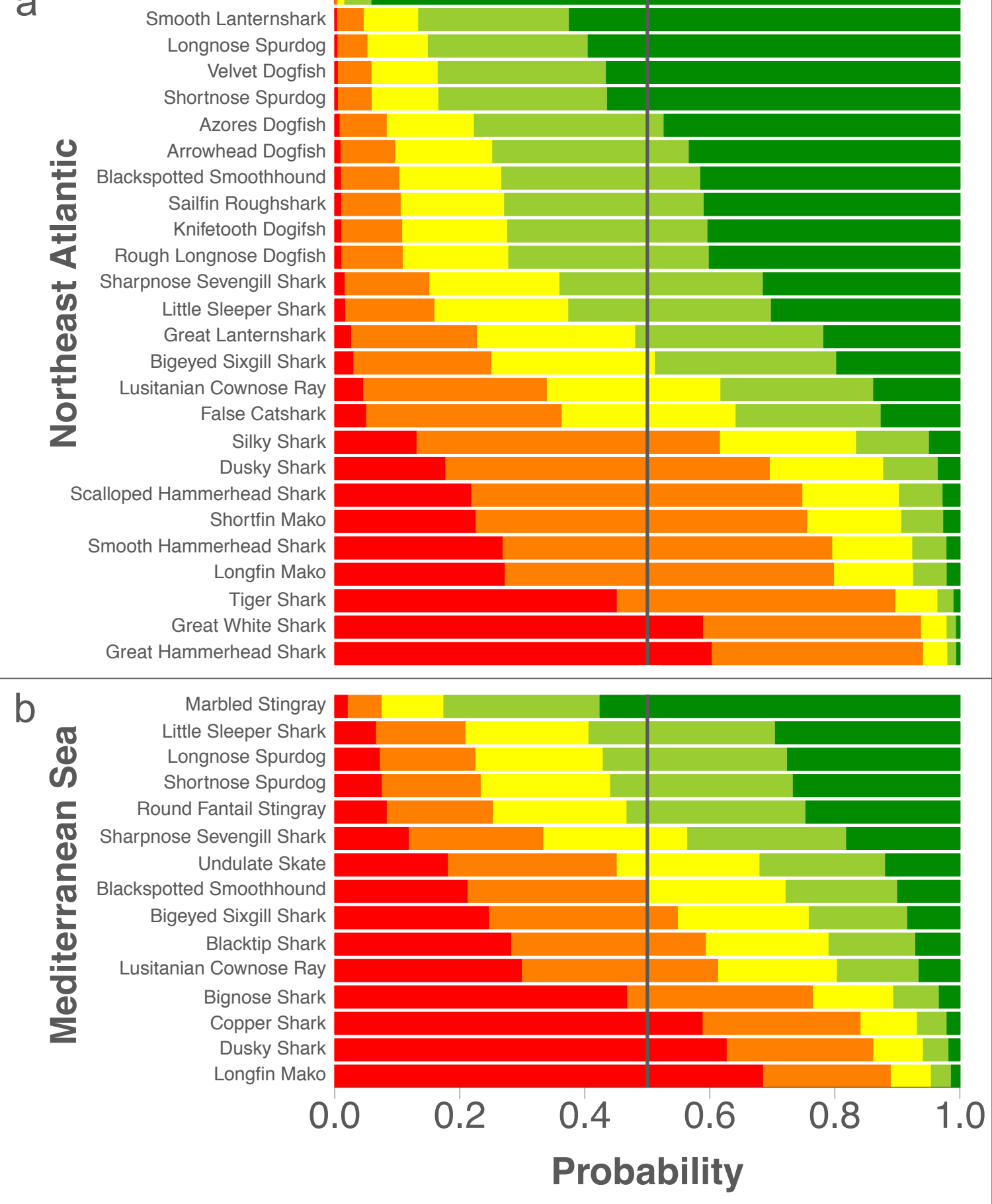

Mediterranean Sea

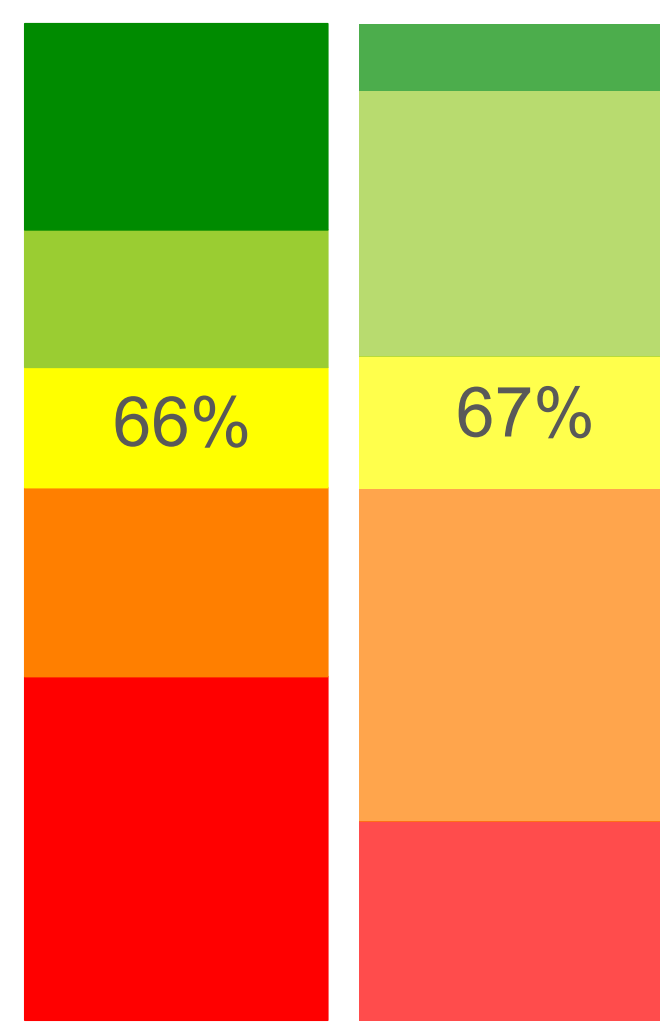

Evaluated

(58)
Predicted

(15)

\section{Least Concern}

Vulnerable

Critically Endangered 


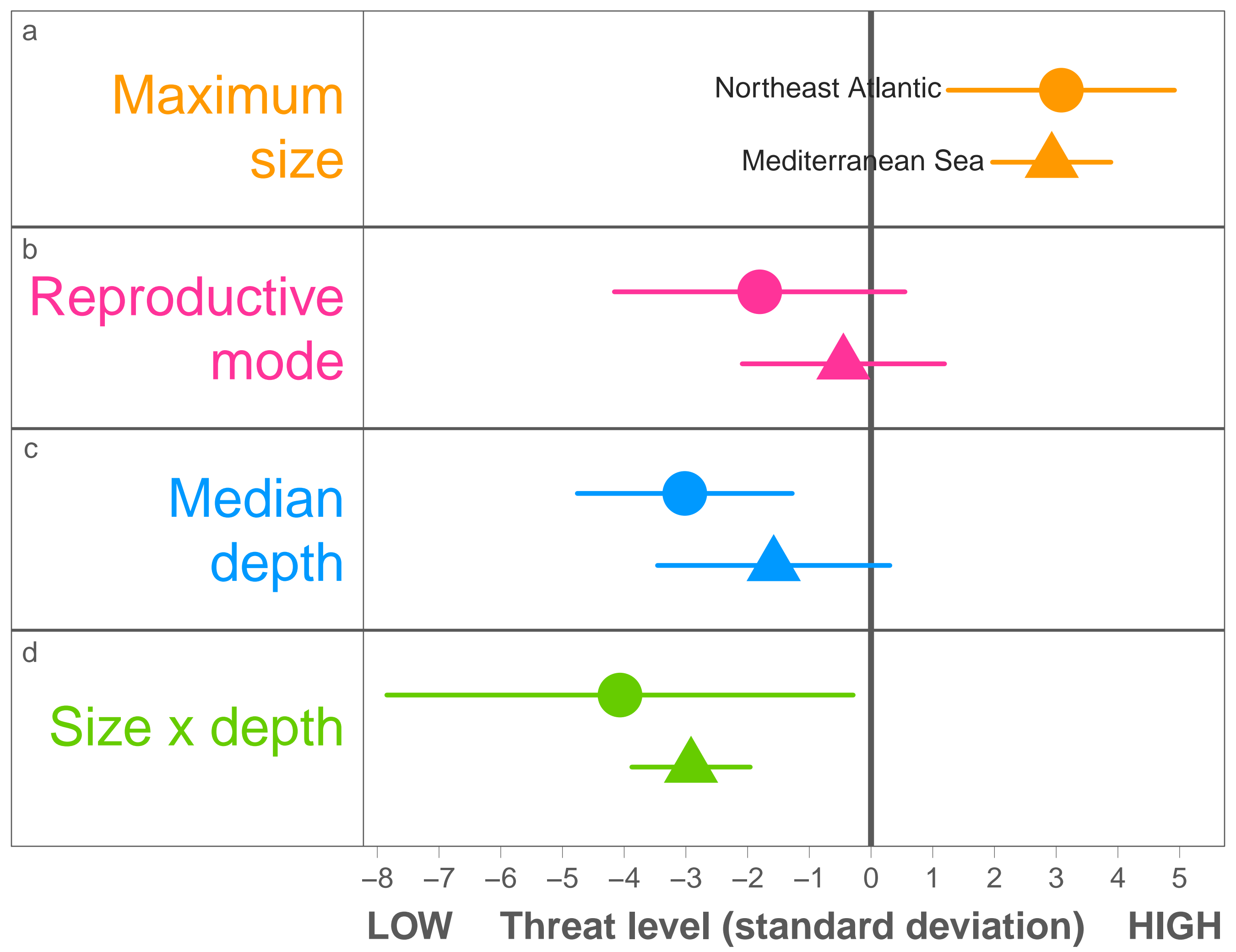




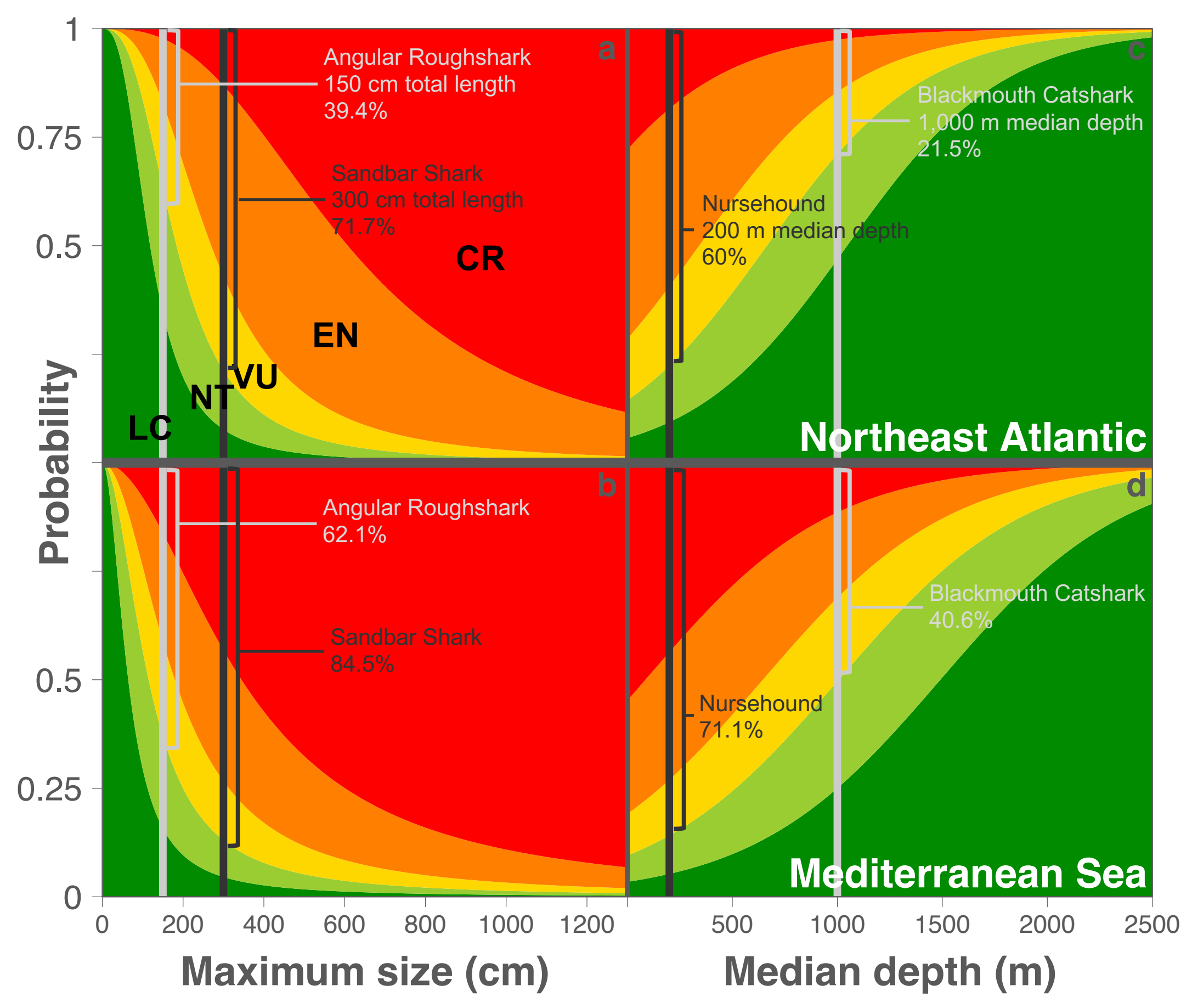

